\title{
The Burgess Shale paleocommunity with new insights from Marble Canyon, British Columbia
}

\author{
Karma Nanglu (D), Jean-Bernard Caron (D), and Robert R. Gaines
}

\begin{abstract}
The middle (Wuliuan Stage) Cambrian Burgess Shale is famous for its exceptional preservation of diverse and abundant soft-bodied animals through the "thick" Stephen Formation. However, with the exception of the Walcott Quarry (Fossil Ridge) and the stratigraphically older Tulip Beds (Mount Stephen), which are both in Yoho National Park (British Columbia), quantitative assessments of the Burgess Shale have remained limited. Here we first provide a detailed quantitative overview of the diversity and structure of the Marble Canyon Burgess Shale locality based on 16,438 specimens. Located $40 \mathrm{~km}$ southeast of the Walcott Quarry in Kootenay National Park (British Columbia), Marble Canyon represents the youngest site of the "thick" Stephen Formation. We then combine paleoecological data sets from Marble Canyon, Walcott Quarry, Tulip Beds, and Raymond Quarry, which lies approximately $20 \mathrm{~m}$ directly above the Walcott Quarry, to yield a combined species abundance data set of 77,179 specimens encompassing 234 species-level taxa. Marble Canyon shows significant temporal changes in both taxonomic and ecological groups, suggesting periods of stasis followed by rapid turnover patterns at local and short temporal scales. At wider geographic and temporal scales, the different Burgess Shale sites occupy distinct areas in multivariate space. Overall, this suggests that the Burgess Shale paleocommunity is far patchier than previously thought and varies at both local and regional scales through the "thick" Stephen Formation. This underscores that our understanding of Cambrian diversity and ecological networks, particularly in early animal ecosystems, remains limited and highly dependent on new discoveries.
\end{abstract}

Karma Nanglu. * Department of Ecology and Evolutionary Biology, University of Toronto, Toronto, Ontario M5S 2J7, Canada, and Department of Natural History Paleobiology, Royal Ontario Museum, Toronto, Ontario M5S 2C6, Canada. E-mail: nangluk@si.edu

*Present address: Department of Paleobiology, Smithsonian Institution, 10th Street \& Constitution Avenue NW Washington, D.C. 20560, U.S.A.

Jean-Bernard Caron. Department of Natural History Paleobiology Section, Royal Ontario Museum, Toronto, Ontario M5S 2C6, Canada, Department of Ecology and Evolutionary Biology, University of Toronto, Toronto, Ontario M5S 2J7, Canada, and Department of Earth Sciences, University of Toronto, Toronto, Ontario M5S 3B1, Canada. E-mail: jcaron@rom.on.ca

Robert R. Gaines. Geology Department, Pomona College, 185 East Sixth Street, Claremont, California 91711, U.S.A. E-mail: Robert.Gaines@pomona.edu

Accepted: 11 December 2019

Data available from the Dryad Digital Repository: https://doi.org/10.5061/dryad.wstqjq2gd

\section{Introduction}

The ca. 506-Myr Burgess Shale, located in the Canadian Rockies of British Columbia, is among the most celebrated KonservatLagerstätten in the world thanks to the exceptional preservation of abundant and diverse assemblages of soft-bodied animals. For more than $100 \mathrm{yr}$, the Burgess Shale fauna has provided critical insights into the morphology and evolutionary relationships of some of the oldest members of many metazoan groups within the broader context of the Cambrian radiation of animal life (e.g., Erwin et al. 2011). In addition to these contributions to evolutionary studies, the Burgess Shale and other similar deposits like the Chengjiang biota of South China (Zhao et al. 2013) offer a far more complete view of Cambrian marine life than do normal fossil deposits of the same age (Conway Morris 1986).

This view has been expanded by the discovery of new Cambrian localities with soft-tissue preservation, in particular in the southern Canadian Rockies (Collins et al. 1983; Fletcher and 
Collins 1998, 2003; Johnston et al. 2009; Caron et al. 2010), underscoring that the Burgess Shale paleocommunity is a mosaic of multiple local communities. However, rigorous, quantitative paleocommunity analyses that incorporate both abundances and stratigraphic data have been largely focused on the Walcott Quarry, the best-sampled and most intensively studied site (however, see Zhao et al. [2012, 2013] for two exceptions from China). These studies, spurred by large amounts of additional fossil material collected by the Royal Ontario Museum in the 1990s, have not only shown how varied the Burgess Shale is in both taxonomic composition and diversity of life habits, but also how the paleocommunity changed throughout the Walcott Quarry interval (Caron and Jackson 2006, 2008). Subsequent comparisons with the Tulip Beds, located approximately $4 \mathrm{~km}$ southwest from the Walcott Quarry on Mount Stephen, revealed that only half of the genera of the Tulip Beds are shared with the Walcott Quarry (O'Brien and Caron 2015). Despite these differences, however, the major taxonomic groups (Arthropoda, Porifera, Priapulida, and Brachiopoda) and ecological modes (epibenthic suspension feeders and nektobenthic predators) were broadly similar at the two localities (O'Brien and Caron 2015). Taken together, these results suggested that while environmental conditions may have caused some change in the ecological structure of the Burgess Shale paleocommunity over short intervals, at a broader scale (including older sites in China) Cambrian faunas were relatively stable in structure across large geographic and temporal scales (O'Brien and Caron 2015).

These recent studies have begun to elucidate a broader picture of Cambrian paleocommunity ecology. However, to fully investigate local and regional variations of the Burgess Shale paleocommunity composition, as well as the ecological and environmental factors responsible for those variations, analyses including additional localities that provide a greater breadth of both time and spatial extent are required. The lack of a unified data set incorporating fine-scale temporal variations in composition between multiple Burgess Shale localities has also precluded a broader quantitative assessment of the Burgess Shale paleocommunity as a whole. Consequently, the utility of the Burgess Shale as a point of comparison with modern ecological dynamics (faunal turnover, spatial and temporal heterogeneity, etc.) has remained limited.

Here we provide a detailed overview of the paleocommunity diversity and structure of the Burgess Shale at the Marble Canyon fossil locality (Caron et al. 2014). Discovered in 2012, Marble Canyon is the second most intensively sampled Burgess Shale locality after the Walcott Quarry, with major quarrying operations led by the Royal Ontario Museum in 2014 and 2016. Marble Canyon has already revealed key insights into a number of major animal groups such as Arthropoda (Aria and Caron 2015, 2017, 2019; Aria et al. 2015; Moysiuk and Caron 2019) Chordata (Conway Morris and Caron 2014), Lophophorata (Moysiuk et al. 2017), Hemichordata (Nanglu et al. 2016), and Annelida (Nanglu and Caron 2018).

We then integrate these data with a census of fossils collected by the Royal Ontario Museum in the 1990s from a roughly 2-m-thick interval from the Raymond Quarry (Fletcher and Collins 1998). With the exception of an unpublished M.S. thesis (Devereux 2001), the Raymond Quarry, which is one of the most extensively sampled Burgess Shale sites, has yet to be fully described in a quantitative paleocommunity framework. The collecting strategy employed at both Marble Canyon and Raymond Quarry - centimetric stratigraphic sampling-allows for uncommonly highresolution consideration of temporal change within the paleocommunity, a scale broadly comparable to the Walcott Quarry. Integrating the Marble Canyon, the Walcott Quarry (Caron and Jackson 2008; O'Brien and Caron 2015), the Tulip Beds (O'Brien and Caron 2015), and the Raymond Quarry (Fig. 1A), represents the largest Cambrian Burgess Shale-type paleocommunity analysis to date.

Geologic Setting, Temporal Scales, and Taphonomic Considerations. - The Marble Canyon fossil site (MC) is located in Kootenay National Park, British Columbia, Canada, approximately $40 \mathrm{~km}$ southeast of the Walcott Quarry in Yoho National Park, and is inferred to be the youngest Burgess Shale paleocommunity based on biostratigraphic evidence and 

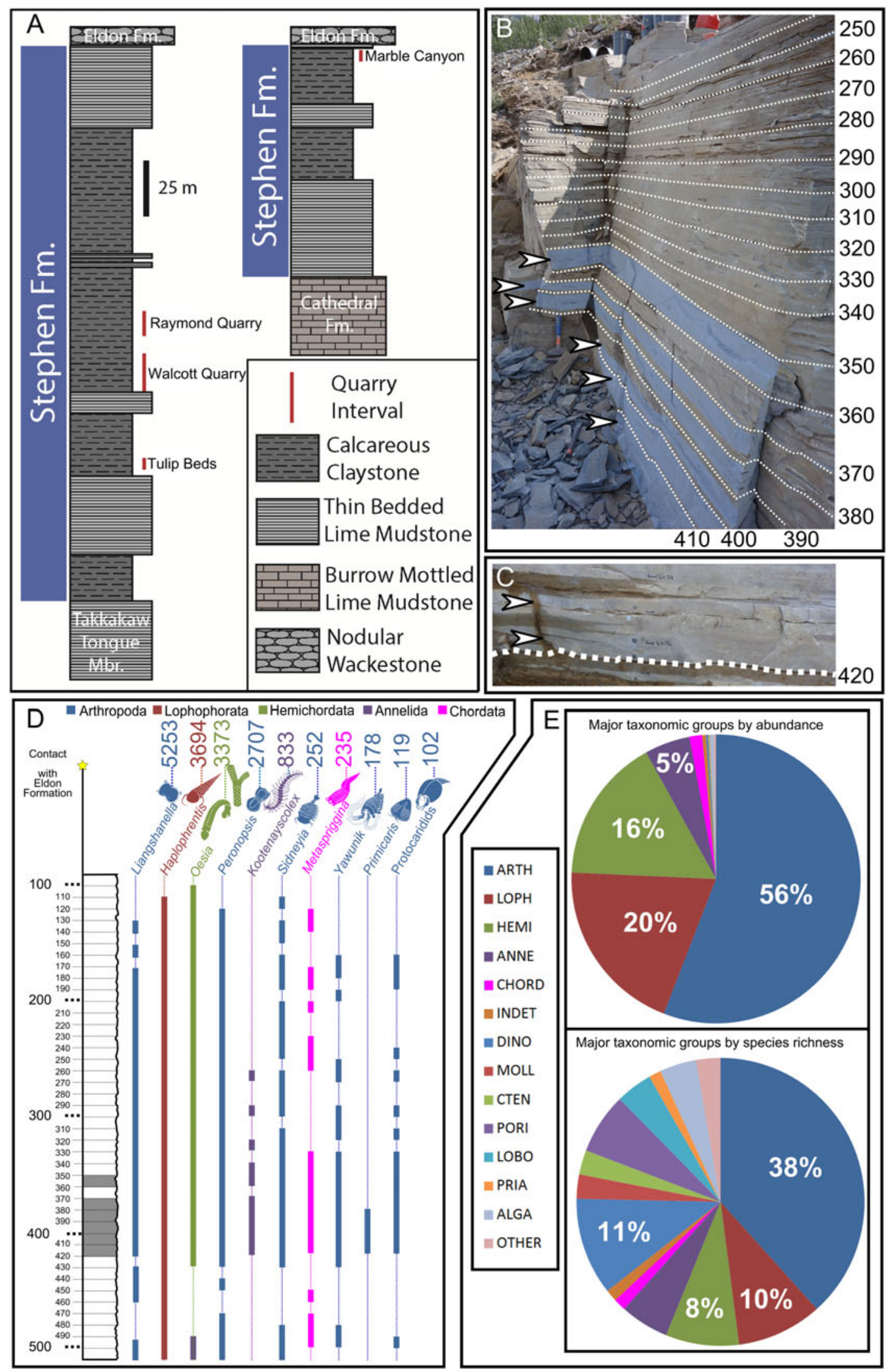
stratigraphic position (Caron et al. 2014). The Marble Canyon quarry is located near the top of the "thick" Stephen Formation (Fig. 1A), immediately underneath the contact with the overlying Eldon Formation. This high position within the "thick" Stephen Formation is in sharp contrast to other Burgess Shale localities at Fossil Ridge, on Mount Stephen, and on Odaray Mountain, which lie in the lower and middle portions of the formation (Collins et al. 1983; Fletcher and Collins 1998, 2003; O'Brien et al. 2014).

Although the Cathedral Escarpment is not exposed in the Marble Canyon area, as it is in the type area (Aitken 1997; Fletcher and Collins 1998, 2003), several factors indicate that the "thick" Stephen Formation at Marble Canyon was deposited on a sloping surface immediately offshore of a pronounced break in submarine topography. The "platformal" or "thin" Stephen Formation (e.g., Aitken 1997), which is immediately adjacent to the Marble Canyon locality $(<300 \mathrm{~m})$, is organized into a series of seven depositional parasequences, reflecting the control of sea-level variations over its stratigraphic expression (Caron et al. 2010; Gaines 2014). No such depositional cyclicity is evident in the "thick" or "basinal" Stephen Formation at Marble Canyon, indicating deposition in a comparably deep-water setting that was not influenced by changes in sea level (Caron et al. 2014). Furthermore, the section at Marble Canyon is characterized by prevalence of slumps, slide masses, and other manifestations of soft-sediment deformation (Caron et al. 2014). Together, these factors point to a sharp slope break, which may have taken the form of a near-vertical escarpment, as in the type area, or an oversteepened slope that descended to the basin. Regardless, these features demonstrate that an overall similar biostratinomic setting was shared among all Burgess Shale sites at Marble Canyon and in Yoho National Park. Fossil assemblages were rapidly entombed in fine-grained claystones in settings that lay near the foot of the Cathedral Escarpment, or in the case of Marble Canyon, at its distal sloping surface, in relatively close proximity to their living environments (Caron and Jackson 2006; Gaines 2014).

At Marble Canyon and the three other localities considered here, fossils were preserved via a globally distributed taphonomic pathway referred to as "Burgess Shale-type preservation" (Butterfield 1995; Gaines 2014), by which whole assemblages of soft-bodied organisms were preserved as primary organic remains. This mode of fossilization, which resulted from early suppression of microbial decomposition in the sediments of the early burial environment (Gaines et al. 2012), is widespread in early Phanerozoic strata and is much less common thereafter (Butterfield 1995), a pattern that has been linked to changes in seawater chemistry (Gaines et al. 2012). The four assemblages considered here reflect highly consistent biostratinomic and early diagenetic conditions. In addition, the presence of abundant and pristinely preserved vermiform enteropneusts (Oesia disjuncta) across most of the Marble Canyon quarry interval suggests little pre- or postmortem transport or decay (Nanglu et al. 2015; Beli et al. 2017), similar to Walcott Quarry (Caron and Jackson 2008), the Tulip Beds

\footnotetext{
FIGURE 1. Stratigraphic column including four major Burgess Shale localities and broad diversity trends at Marble Canyon. A, Stratigraphic column of the Stephen Formation with the relative positions of the four included localities shown in red. The Eldon Formation-Stephen Formation contact point lies $1 \mathrm{~m}$ directly above the Marble Canyon quarry. B, The Marble Canyon quarry. Dashed lines indicate bedding horizons; the adjacent numbers indicate their relative positions in negative centimeters from the Eldon Formation-Stephen Formation contact point. Arrows indicate the sample intervals (highlighted in blue), which contain thick bedding intervals that are particularly fossiliferous. C, Close-up of the lowest thick bedding intervals at Marble Canyon quarry, indicated by arrows. D, The top 10 most abundant taxa belong to a mix of different taxonomic groups, but are dominated by arthropods (number of specimens of each taxon indicated above the respective names). The first four most abundant taxa are stratigraphically widespread throughout the quarry; the next six are more restricted (with the exception of Sidneyia). Stratigraphic subunits colored in gray represent intervals with thick bedding layers. Stratigraphic intervals measured in $\mathrm{cm}$ below the Eldon Formation-Stephen Formation contact point. E, Major taxonomic groups represented at Marble Canyon by abundance and diversity. Arthropods dominate both categories, but lophophorates, hemichordates, and annelids are also significant components of the paleocommunity. Acronyms: ALGA, algae; ANNE, Annelida; ARTH, Arthropoda; CHORD, Chordata; CTEN, Ctenophora; DINO, Dinocaridida; HEMI, Hemichordata; INDET, indeterminate taxon; LOBO, Lobopodia; LOPH, Lophophorata; MOLL, Mollusca; OTHER, all other taxa not listed; PORI, Porifera; PRIA, Priapulida.
} 
(O'Brien et al. 2014), and likely the Raymond Quarry, based on disparate suites of soft-bodied organisms of low preservation potential.

Although the "thick" Stephen Formation at Marble Canyon exhibits major differences in thickness and stratigraphy from those localities of the type area in Yoho National Park (Fletcher and Collins 1998; Caron et al. 2014), the upper and lower contacts of the "thick" Stephen Formation provide excellent markers of regional environmental changes (e.g., Aitken 1997) and allow for ordering of the four localities in relative time, with Marble Canyon being the youngest site, followed by Raymond Quarry, Walcott Quarry, and Tulip Beds (Fig. 1A). Biostratigraphically, the "thick" Stephen Formation lies between the overlying trilobite Ptychagnostus gibbus Zone and the underlying Glossopleura Zone (Sundberg 1994). According to published time-calibrated biostratigraphic schemes, this interval could potentially represent less than 200,000 yr (Peng et al. 2012). At Marble Canyon, the mudstones of the "thick" Stephen Formation correspond to approximately $35 \mathrm{~m}$ of strata (Caron et al. 2014), yielding a very crude time estimate of ca. $1.75 \mathrm{~m} / 10 \mathrm{kyr}$, assuming that sediment accumulation rates were relatively constant at the meter scale. However, the 4-m-thick Marble Canyon quarry lies at the top of the "thick" Stephen Formation within the upper part of the Ehmaniella burgessensis faunule of the Ehmaniella biozone (Sundberg 1994; Caron et al. 2014). In this quarry interval (and all the other quarry intervals studied herein), the presence of several centimeter scale-event deposited claystones (Caron et al. 2014), suggests a shorter timescale than the one calculated based on constant sedimentation rates (i.e., at Marble Canyon <24,000 yr). In the Fossil Ridge area, the "thick" Stephen Formation encompasses $140 \mathrm{~m}$ of strata (Fletcher and Collins 1998), yielding a comparably crude accumulation rate of $7 \mathrm{~m} / 10 \mathrm{kyr}$, making the same assumptions as above. This approach yields a maximum estimate of ca. 10,000 yr for the deposition of the 7-m "Greater Phyllopod Bed," which is consistent with the lower boundary estimate already calculated for this interval (e.g., Caron and Jackson 2008). With the same accumulation rate, the 2-m-thick interval of the Raymond Quarry studied herein would roughly represent $3000 \mathrm{yr}$, and the interval separating the Walcott and Raymond quarries (approximately $20 \mathrm{~m}$; Fletcher and Collins 1998), ca. 30,000 yr. The span of time between the Tulip Beds and the Walcott Quarry or the Raymond Quarry and Marble Canyon are less constrained owing to lateral stratigraphic variations between outcrops. It is important to underscore that these estimates are very poorly constrained, but nevertheless they are conservative and suggest that each assemblage represents no more than a few thousands of years and that assemblages are separated by intervals of a few tens of thousands of years.

\section{Materials and Methods}

Field collections at Marble Canyon (MC) were conducted in 2012, 2014, and 2016, yielding a total of 21,687 individual specimens (field observations and collected specimens) representing 73 species. The contact point between the Stephen Formation and the overlying Eldon Formation was used as a reference point for stratigraphic measurements, with specimens measured in centimeters below this contact (Fig. 1B). Stratigraphic level was recorded for all specimens included in subsequent quantitative analyses. Due to prominent lateral variation in bedding throughout the quarry interval, fossils were organized into 10-cm-thick stratigraphic subunits henceforth referred to as sample intervals (SI), which represent multiple discrete burial events. SIs are composed of tens to roughly 100 claystone beds, ranging from 1 to $37 \mathrm{~mm}$ in thickness. Thus the sum of all fossils collected within a 10-cm-thick SI, typically representing dozens of burial events, constitutes an induced time-average assemblage of roughly $600 \mathrm{yr}$ in duration (see previous section).

SIs with a total specimen count under 299 were removed to acknowledge possible undersampling effects; a comparable threshold number was used for the Walcott Quarry in previous analyses (Caron and Jackson 2008). The resultant species abundance matrix included 18 SIs from Marble Canyon, the uppermost of which ends $230 \mathrm{~cm}$ below the Eldon-Stephen contact (Fig. 1C). In total, 16,438 specimens 
were included in all analyses of faunal composition, diversity, and turnover at MC.

Specimens were identified to the species level whenever possible, and abundance was tabulated using complete censuses of slab surfaces following methodologies used in previous quantitative studies of the Burgess Shale (Caron and Jackson 2006, 2008; O'Brien and Caron 2015). In particular, some specimens were identified based on disarticulated or dissociated material, including carapaces of bivalved arthropods such as Tokummia katalepsis, hurdiid carapaces such as Hurdia sp., or the myomeres of Metaspriggina sp. In rare instances, the number of specimens from surfaces composed exclusively of shelly taxa such as Haplophrentis carinatus or Ptychagnostus sp., with individuals typically overlapping one another, were estimated using the density of a $2 \mathrm{~cm}^{2}$ square and extrapolating to the total surface area covered by those specimens.

Other Burgess Shale Localities.-The Walcott Quarry (WQ) is located on Fossil Ridge between Mount Wapta and Mount Field and is part of the Walcott Quarry Member of the "thick" Stephen Formation (Fletcher and Collins 1998; Caron and Jackson 2006). We used the data set originally published by Caron and Jackson (2008) and updated by O'Brien and Caron (2015) for our quantitative analyses. This data set comprised 43,296 specimens, divided stratigraphically into 26 SIs with more than 300 collected specimens each.

The Raymond Quarry (RQ) is located approximately $20 \mathrm{~m}$ above the base of the Greater Phyllopod Bed of the Walcott Quarry (Raymond Quarry Member; Fletcher and Collins 1998, 2003). A total of 9539 observations were made systematically from a 2.3-m-thick stratigraphic section using the same methodology as for the $\mathrm{MC}$, using $10 \mathrm{~cm}$ bins to create SIs roughly comparable with those of the MC. We identified 114 taxa from this relatively restricted stratigraphic section of the $R Q$, with dominant taxa being the arthropod Leanchoilia, the sponge Choia, and the priapulid Ottoia.

The Tulip Beds (TB) locality on Mount Stephen, which occurs within the Campsite Cliff Shale Member of the "thick" Stephen Formation, was described in O'Brien et al. (2014) and O'Brien and Caron (2015). Although the middle and upper parts of the "thick" Stephen Formation are not present at the TB locality, extrapolation from Mount Stephen to the nearby $(<2 \mathrm{~km})$ complete section on Mount Field reveals that the Campsite Cliff Shale Member lies below the Walcott Quarry Member (Fletcher and Collins 1998, 2003). This locality shares roughly $50 \%$ of its genera with the Walcott Quarry and is largely dominated by an indeterminate egg-shaped taxon, the tulip animal Siphusauctum gregarium, the alga Marpolia spissa, and the predator Anomalocaris canadensis. A total of 7906 specimens (the data set from O'Brien and Caron [2015]) from the Tulip Beds were included in our analyses. These specimens were analyzed as a bulk assemblage (O'Brien et al. 2014).

With all four localities combined, our ecological data matrix includes abundance patterns for 77,179 specimens of 234 taxa (Supplementary Tables 1-3).

Diversity Patterns and Multivariate Analyses.-Rarefaction curves were produced in PAST. All other quantitative data was prepared in Microsoft Excel and analyzed in R using the following packages: vegan, MASS, analogue, dendextend, dplyr, indicspecies, and ggplot 2 .

Rarefaction curves were used to determine the extent to which the MC locality had been adequately sampled to recover the majority of the true total species richness. Whittaker plots (also called rank abundance curves) were also plotted for the three richest and poorest SIs to observe how paleocommunity structure may be influenced by patterns of evenness/dominance of species abundances.

Cluster analysis (performed in $\mathrm{R}$ using the function hclust with complete linkage) was used to identify major groups of subunits sharing similar species or ecological compositions. We used the Morisita-Horn overlap index to generate the ecological distance matrices, which is a common metric that has been demonstrated to be robust to variation in sample sizes (Magurran 2004; Barwell et al. 2015).

Correspondence analysis (CA), a method of ordination (Gauch 1982; Legendre and Legendre 2012) was chosen to visualize the scores of species and sampling intervals into two dimensions. CA is a commonly used method for exploring paleocommunity data 
sets (Hammer and Harper 2006), including previous studies of the Burgess Shale (Caron and Jackson 2006, 2008) and the Chengjiang biota (Zhao et al. 2013). CA does not make presuppositions regarding the presence or absence of an environmental gradient in the data set, although this method expects a unimodal distribution of the species (Gauch 1982; Legendre and Legendre 2012). Eigenvalues returned by CA, while less straightforward to interpret than in an ordination technique such as principal components analysis, represent a proportion of the variance among the data set explained by their respective axes (Legendre and Legendre 2012). CA of the Burgess Shalewide data set showed an arch effect, which is a common artifact resulting from the driving factors influencing the plotting of the first correspondence axis also affecting the second axis. To accommodate for this effect, detrended correspondence analysis (DCA) was used, which is a method specifically designed to remove distorting properties of arch effects (Legendre and Legendre 2012).

When performing CA and DCA, the raw data matrix of species abundances by site was first standardized by column and row weights, which are calculated by dividing the sum of all the values in the respective column or row by the sum of the values of the entire table (Legendre and Legendre 2012; Oksanen et al. 2019). In both CA and DCA, (1) sites similar in species composition should appear close to each other along at least one axis; (2) species should appear close to sites in which they are abundant; (3) species should appear close to other species with similar distributions across sites; and (4) species that are abundant across multiple sites should appear toward the center of the ordination, while those that are rare across most sites are plotted at the edges (Hammer and Harper 2006; Legendre and Legendre 2012).

Finally, species indicator analysis was used to identify species that may be uniquely characteristic of a given locality. By providing a priori knowledge of how particular sites are grouped, this method calculates an indicator statistic for each species in the paleocommunity data matrix that takes into account: (1) specificity, that is, the likelihood of the sampled site (in this case, SI) belonging to a target site group (in this case, a locality of $\mathrm{WQ}, \mathrm{TB}, \mathrm{RQ}$, or $\mathrm{MC}$ ) given that the species has been found; and (2) fidelity, that is, the probability of finding the species at any sites belonging to the target site group (De Cáceres et al. 2012). An indicator taxon is one that is, therefore, both highly specific to and relatively ubiquitous at a given locality or combination of localities.

Ecological Groups and Functional Diversity.The ecological mode was described using a modified version of a previously published three-axis system (Bambach et al. 2007). This system posits that the ecological mode of the vast majority of marine taxa can be described using three variables: (1) the vertical position within the water column they occupied, (2) their motility, and (3) their trophic strategy. This framework has been used in other analyses of Cambrian fauna (Conway Morris 1986; Caron and Jackson 2008; Zhao et al. 2013; O'Brien and Caron 2015) and is particularly useful when considering animal communities that incorporate a wide variety of phyla. While admittedly overgeneralized in some cases, this approach can accommodate the wide variety of ecologies employed by the considerable disparity of body plans represented by a well-preserved marine locality. We then constructed an ecological-group matrix whereby each taxon was assigned an ecological mode using the three-axis system. This data set was then analyzed using cluster analyses, CA and DCA (as described earlier).

\section{Results}

Diversity Patterns at Marble Canyon.--In total, 73 species-level taxa are present at MC, most coming from discrete bedding intervals appearing black in outcrop (Fig. 1B,C). Abundant species tend to recur across the studied interval (e.g., Liangshanella, Haplophrentis, Oesia, and Peronopsis), while others have patchier temporal distributions (e.g., Yawunik; Fig. 1D). Kootenayscolex and Primicaris seem particularly abundant in SIs characterized by thicker beds (between SI 420 and SI 350; Fig. 1D). As is the case in all major studied Burgess Shale sites (Conway Morris 1986; Caron and Jackson 2008; O'Brien and Caron 2012), arthropods are the most abundant and diverse 

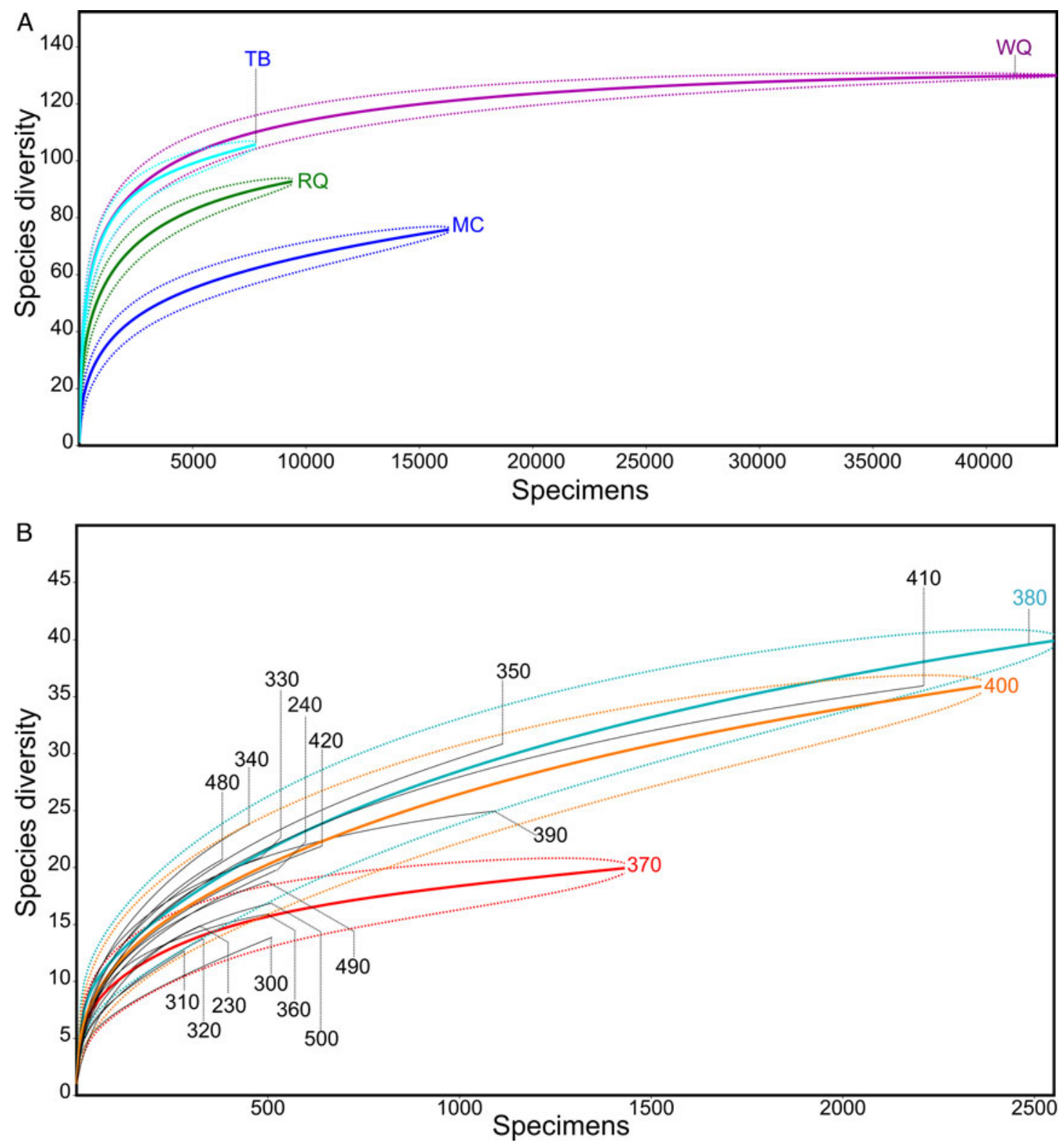

FIGURE 2. Rarefaction curves for the four studied Burgess Shale localities at the level of bulk assemblages, and the individual Marble Canyon (MC) quarry sample intervals (SIs). A, At the bulk assemblage level, rarefaction curves have generally plateaued, suggesting that they have been sampled sufficiently for diversity comparisons (95\% confidence intervals in dashed lines of the same color as their respective locality). B, Rarefaction curves for the Marble Canyon SIs. For clarity, the $95 \%$ confidence intervals (dashed lines) are only plotted for SI 370, SI 380, and SI 400. RQ, Raymond Quarry; TB, Tulip Beds; WQ, Walcott Quarry.

major taxonomic group (Fig. 1D). However, in no other Burgess Shale sites are hemichordates, annelids, or chordates such significant components of the paleocommunity, at $16 \%, 5 \%$, and $1.3 \%$ by abundance, respectively. When considering diversity irrespective of abundance, we found a substantial number of radiodonts, which constitute roughly $11 \%$ of the total species richness, many of which are currently undescribed forms (Fig. 1D).

The slope of the rarefaction curve for the Marble Canyon as a bulk assemblage, 


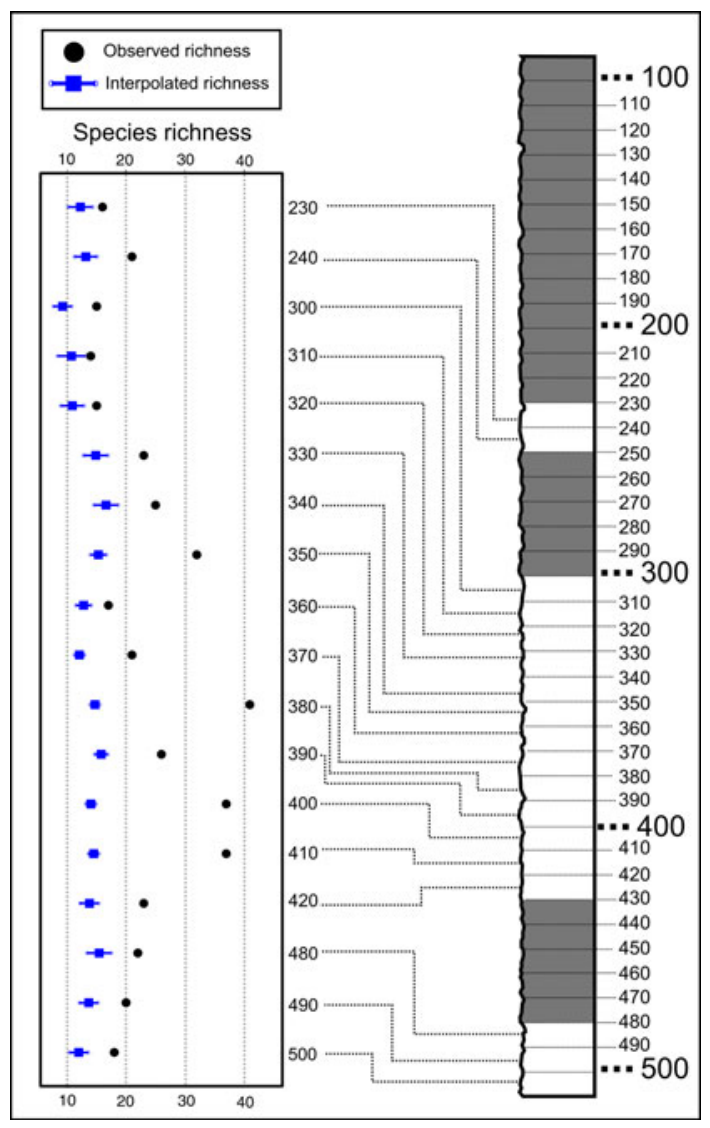

FiguRE 3. Observed and interpolated species richnesses across sample intervals (SIs) with 95\% confidence intervals. Only SIs with more than 299 specimens were included in quantitative analyses (SIs with fewer than 299 specimens are grayed out in the stratigraphic column to the right). Interpolating species richnesses to 299 specimens erases most patterns of fluctuating diversity.

compared with the Walcott Quarry, Raymond Quarry, and Tulip Beds bulk assemblages, suggests that while all localities have been sufficiently sampled to capture most of the species richness, Marble Canyon has the greatest potential (the curve is furthest from reaching an asymptote) for new species discovery with continued sampling (Fig. 2A). SIs 350, 380, 400 , and 410 have the highest observed species richness, while SIs 300, 310, and 320 have the lowest (Figs. 2B, 3). The original description of the Marble Canyon assemblage suggested a high diversity of arthropods comparable with Walcott Quarry (Caron et al. 2014). This present study confirms this trend with a much larger sample size
(Supplementary Fig. 1), although other taxonomic groups are not as diverse (i.e., sponges), which explains the relatively lower diversity level overall.

Rank abundance curves illustrate two main types of assemblages, the most extreme examples of which are illustrated in Figure 4. Most SIs have relatively steep curves, indicating that their respective temporal subcommunities were numerically dominated by relatively few taxa (Fig. 4). In most cases, these were the four most abundant and stratigraphically wideranging taxa, namely Haplophrentis and Oesia, which are stratigraphically widespread but most dominant between SI 330 and SI 230, and Liangshanella and Peronopsis, particularly below SI 330. SIs with less steep rank abundance curves are indicative of assemblages that are less dominated by a small group of taxa. In addition to having the greatest evenness of species composition, SIs 380, 410, and 350 are also among the most species-rich subunits (Figs. 3, 4).

All SIs at Marble Canyon are dominated by one of three groups: Arthropoda, Hemichordata, or Lophophorata (Fig. 5). Hemichordate and lophophorate dominances are almost entirely due to Oesia and Haplophrentis, respectively. The abundance of other species of hemichordate and lophophorates make up only $1.5 \%$ of the paleocommunity $(0.2 \%$ and $1.3 \%$, respectively). Together, these three dominant groups (Arthropoda, Hemichordata, and Lophophorata) constitute between $81 \%$ (SI 390) and 99\% (SI 230 and SI 500) of the total species abundance, with the upper levels of the quarry (SI 320 and above) dominated by hemichordates and lophophorates and the lower levels dominated by arthropods. This change is due to both the increase in abundance of large predatory arthropods (e.g., Yawunik and Sidneyia) and, more significantly, the increase in abundance of the arthropod Liangshanella, the most abundant taxon in SI 420 to SI 350.

Taxonomic cluster analysis of the Marble Canyon distinguishes two principal clusters (Fig. 6) that we informally call the upper and lower quarry intervals. The lower quarry (LQ) consists of SIs 500 to 480 . The upper quarry (UQ) consists of all other SIs. The UQ is further subdivided stratigraphically into the uppermost 


\section{Rank abundance curves of richest/poorest BAs}

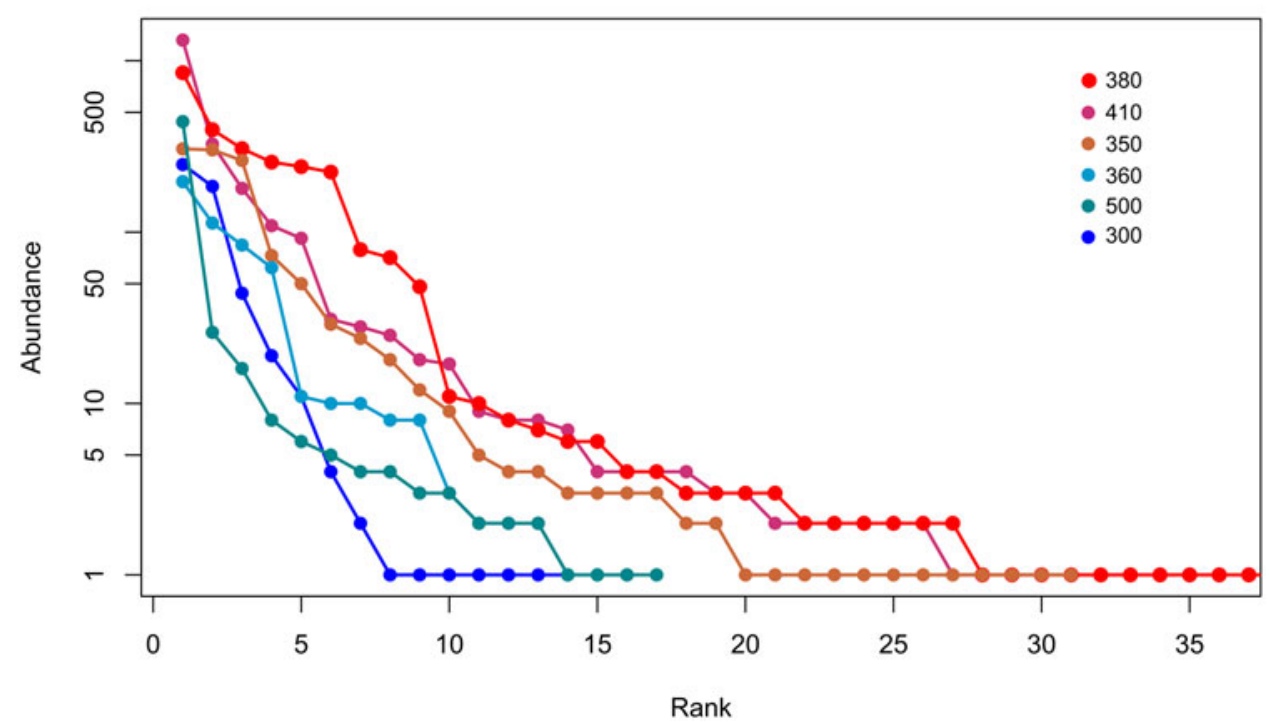

FIGURE 4. Rank abundance curves (also known as Whittaker plots) for the three most species-rich (SI 380, SI 410, and SI 350) and species-poor sample intervals (SI 360, SI 500, and SI 300). A lower slope, as seen in SI 380, SI 410, and SI 350, indicates a greater evenness in abundance among constituent species.

levels of the UQ (SIs 340 to 230; UQ1) and the lower levels of the UQ (SIs 420 to 350; UQ2).

The CA corroborates the division of SIs detected by cluster analysis (Fig. 7). The first two CA axes represent roughly $67 \%$ of the variation among sites. Axis 1 largely defines two major types of assemblages (LQ vs. UQ) and likely represents an environmental factor fluctuating primarily as a function of time. Ptychagnostus and Spartobranchus are strongly associated with the LQ SIs. Axis 2 further discriminates between the UQ1 and UQ2 SIs. Taxa that are highly recurrent throughout the quarry are found close to the center of this axis, such as Yawunik, Sidneyia, Metaspriggina, and Oesia (Fig. 7). Taxa that are abundant but have more stratigraphically structured distributions such as Haplophrentis and Kootenayscolex are plotted farther from the center of the ordination.

Patterns of Ecological Change at Marble Canyon.--In SI 370 and from SI 350 to SI 230, epibenthic-sessile-suspension feeding (ESSU) is the most common ecological mode, generally constituting greater than $50 \%$ of the entire ecological mode occupancy (Fig. 8). In SI 360 as well as SI 420 to SI 380, nektonic-vagrant- hunting/scavenging (NKHS) is the most common ecological mode. In SI 500 to SI 480, nektobenthic-vagrant-deposit feeding (NKDE) is the most common ecological mode. Together, these three ecological modes (ESSU, NKHS, and NKDE) constitute at least $79 \%$ of the total ecological mode occupancy of their respective SIs (SI 390) and at most 97\% (SI 500).

The results of cluster analysis and CA recapitulate the SI-level quantitative patterns of dominance described earlier (Figs. 9, 10). Ecological group 1 (EG1) consists of the SIs dominated by the ESSU ecological mode; ecological group 2 (EG2) consists of the SIs dominated by the NKHS ecological mode; and ecological group 3 (EG3) consists of the SIs dominated by the NKDE ecological mode (Fig. 9). These clusters were used to build the convex hulls in the CA of the Marble Canyon SI-level ecological compositions (Fig. 10). Compared with the other modes, the NKDEdominated SIs (EG3) are far from the center of the ordination, reflecting a clear shift in ecological modes between older (EG3) and younger (EG1 and EG2) intervals.

Overall, we observe long periods of compositional stasis interrupted twice by rapid 


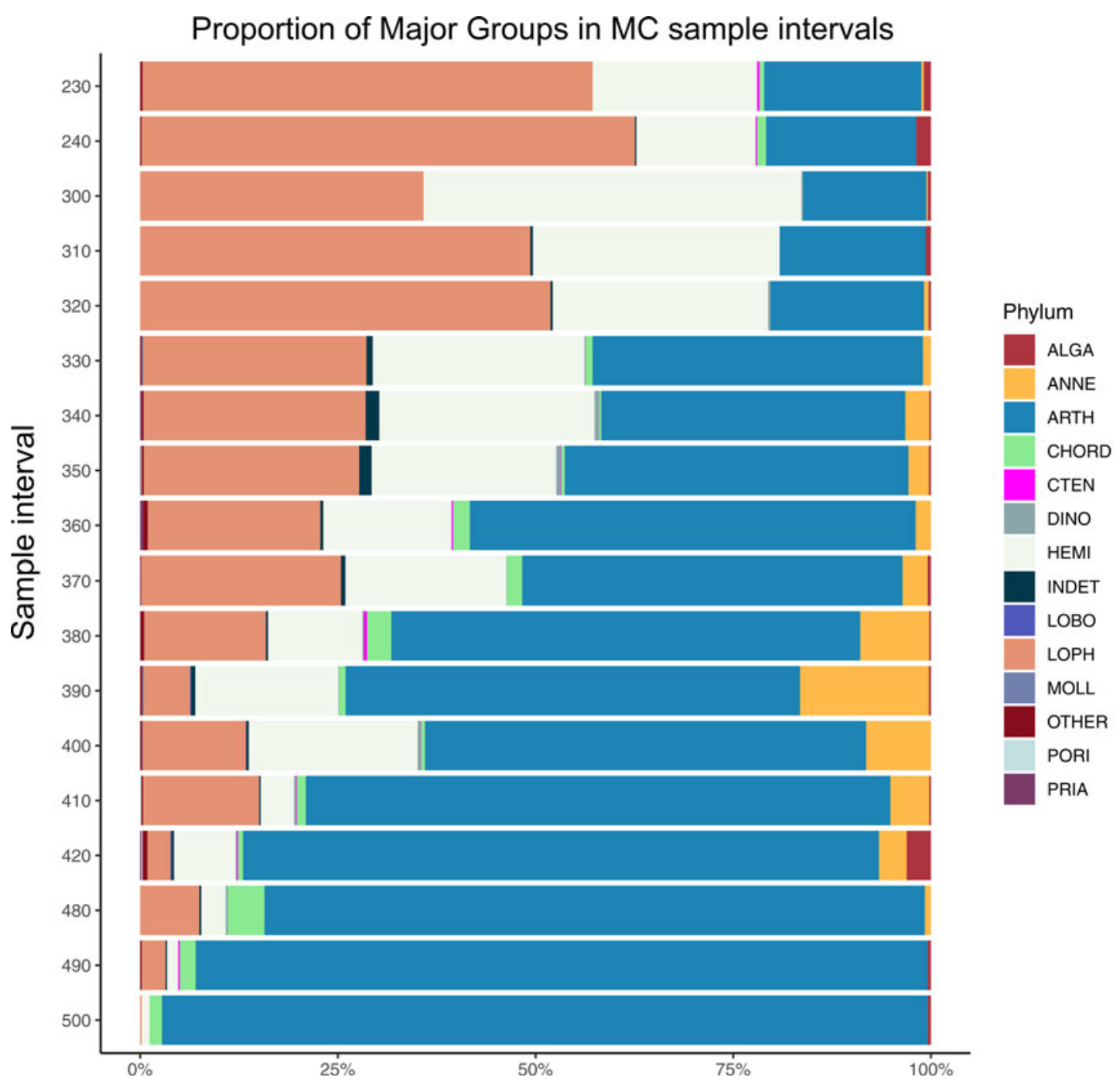

FIGURE 5. Proportions of major taxonomic groups among the Marble Canyon (MC) sample intervals (see Fig. 1). Lophophorates and hemichordates are the most abundant taxa in the upper levels of the quarry. Below SI 340, arthropods become the most numerically dominant major taxon, which persists to the lowest strata of the quarry. Acronyms: ALGA, algae; ANNE, Annelida; ARTH, Arthropoda; CHORD, Chordata; CTEN, Ctenophora; DINO, Dinocaridida; HEMI, Hemichordata; INDET, indeterminate taxon; LOBO, Lobopodia; LOPH, Lophophorata; MOLL, Mollusca; OTHER, all other taxa not listed; PORI, Porifera; PRIA, Priapulida.

changes in species assemblages: once from the LQ (below SI 420) fauna to UQ2, and again from UQ2 to UQ1 (approximately between SI 350 and SI 340). These patterns are closely mirrored using both ecological and taxonomic groups, suggesting that the factors that caused major changes in faunal composition similarly caused a change in the environmental conditions of Marble Canyon, favoring a new faunal assemblage with a new ecological structure than what had existed previously.

Patterns of Ecological Change across the "Thick" Stephen Formation.--Intuitively, most SIs cluster with SIs from the same locality. However, the UQ2 SIs from MC cluster with a subset of the WQ sites, and the LQ SIs cluster with the TB (Fig. 11). The clustering of UQ2 MC and some WQ sites is likely due to the great abundance 


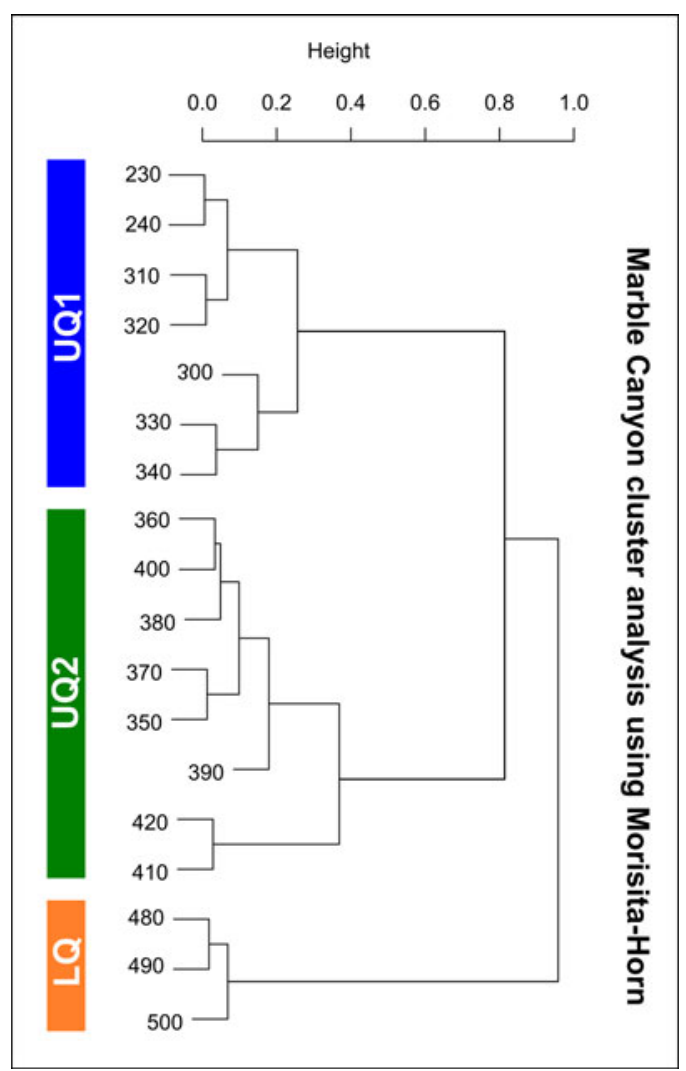

FIgURE 6. Taxonomic cluster analyses for the Marble Canyon Quarry using the Morisita-Horn index support the upper quarry 1 (UQ1), upper quarry 2 (UQ2), and lower quarry (LQ) SIs forming mutually exclusive clusters.

of Liangshanella in these SIs; the clustering of LQ SIs and TB is explained by the presence of Peronopsis, a statistically significant indicator species for an MC + TB-type SI (Table 1).

The first two DCA axes represent $67 \%$ of the total variation among sites (Fig. 12). Four non-overlapping groups of SIs represent MC, WQ, RQ, and TB (Fig. 12), each locality also having unique indicator species, which taken together suggest significant compositional differences between them (Table 1). These groups are easily distinguished on axis 1 (which summarizes $39 \%$ of the variability in the data set), suggesting that the WQ SIs are most representative of the Burgess Shale fauna overall, as they cluster near the center of the ordination. This position might in part reflect the fact that WQ represents the most heavily sampled site with the greatest number of specimens collected. On axis 1, MC and TB are most distant from each other, suggesting these faunas are the most highly differentiated within our data set. Being both the most stratigraphically and geographically disparate pair of localities (MC and TB), axis 1 may then represent a combination of environmental gradients operating at sufficiently large geographic and temporal scales such that the intermediate localities (WQ and RQ) cannot be clearly discriminated from each other on this axis.

Ecologically, four major clusters describe the SIs of our four-locality Burgess Shale data set (Fig. 13); however, each includes stratigraphically disparate SIs. These clusters can be defined by the dominant trophic mode present: the largest cluster represents suspension feeding-dominated SIs and contains SIs from all four localities, including the TB bulk assemblage; the second-largest cluster represents SIs dominated by hunter/scavenger taxa and includes SIs from WQ, RQ, and MC; the last two smaller clusters are dominated by deposit feeders and include SIs from WQ and MC (specifically, the LQSIs from MC). When the results of the cluster analysis are used to plot convex hulls on the CA of the Burgess Shale ecological matrix, there is minimal overlap among these clusters (Fig. 14). The first two CA axes represent greater than $52 \%$ of the total variation, suggesting that the relative proportions of represented trophic modes is of principal importance when defining ecological structure among SIs.

\section{Discussion}

Short Timescale Turnover Patterns of the Burgess Shale Paleocommunity.-Broadly, we can expect the compositional change of ecological communities to conform to one of two sets of patterns. The first pattern is that species or individuals are distributed entirely randomly; this view can be described as the null model of paleocommunity assembly, with the unified neutral theory of biodiversity being its most influential incarnation (Hubbell 2005; Rosindell et al. 2011). Alternatively, paleocommunity composition and change may be structured by a combination of both abiotic and biotic factors, resulting in nonrandom patterns of species distributions over time. There is still considerable debate 


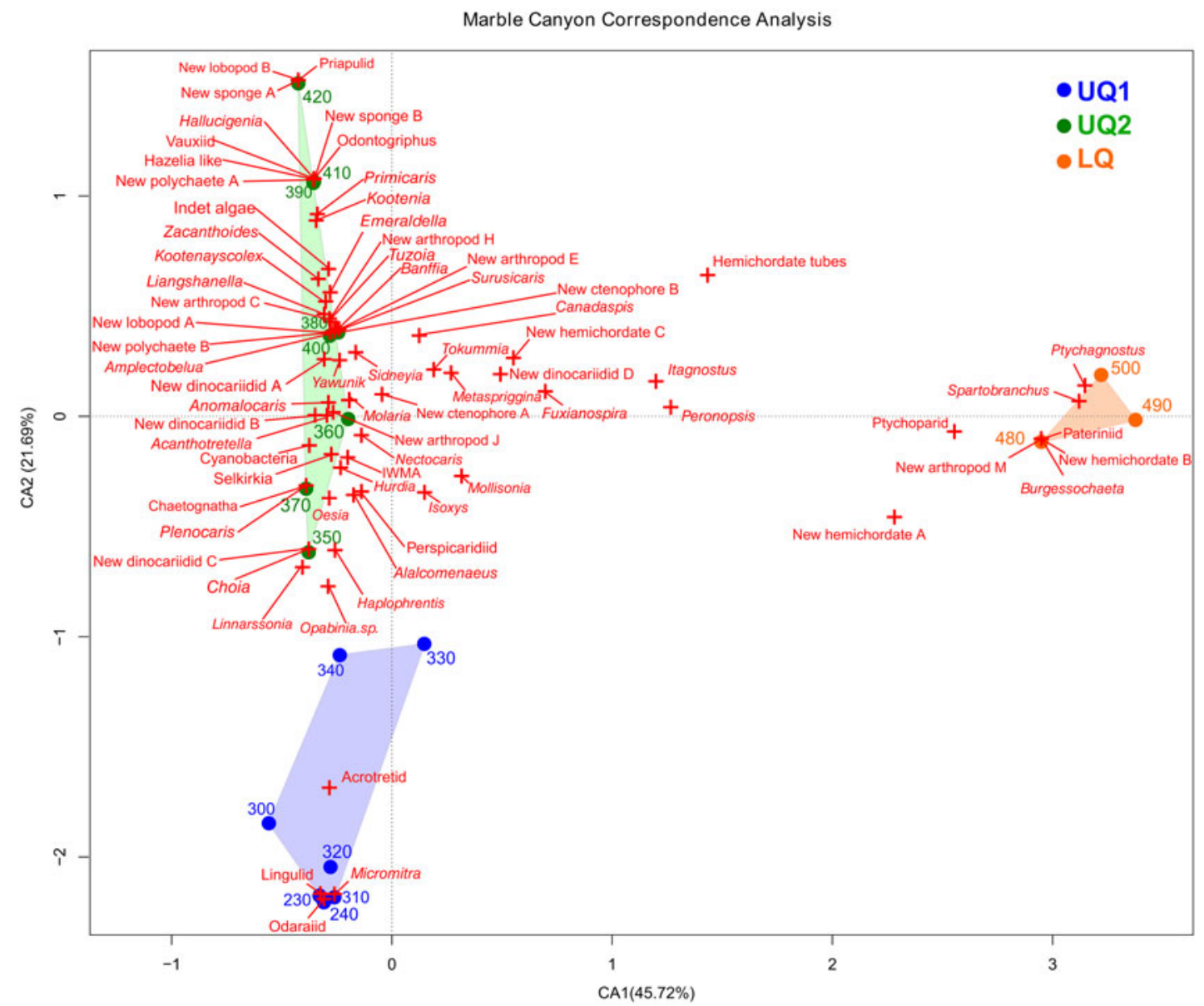

FIGURE 7. Correspondence analysis for the Marble Canyon quarry. Axis 1 delineates the lower quarry from the upper quarry and axis 2 delineates the two subdivisions within the upper quarry: the highest strata, dominated by Oesia and Haplophrentis, and the lower strata of the upper quarry, dominated by Liangshanella and other arthropods.

regarding the relative importance of these factors on community assembly, part of which is due to the temporal constraints of neontological data sets. This is particularly true of experimental studies analyzing trends in diversity change (Simberloff and Wilson 1969; Findlay and Kasian 1986; Condit et al. 1999), but even observational studies rarely span more than a few decades in length (Grant and Grant 2002; Azaele et al. 2006). Paleontological data sets are unique in this regard, providing a much broader temporal sampling than is otherwise possible.

Our data from MC suggest that even at the level of 10-cm-thick SIs, an uncommonly short timescale for a paleontological data set (ca. $600 \mathrm{yr}$ ), the fauna alternated between periods of relative stability and rapid species turnover
(Figs. 5, 6). At Walcott Quarry, this was taken as an indication of periodic environmental disturbance followed by rapid recolonization (Caron and Jackson 2008), often resulting in a very similar fauna between successive SIs. Additionally, most SIs of both quarries are numerically dominated by taxa with broad stratigraphic distributions (Fig. 1). At Marble Canyon, these taxa are Oesia, Haplophrentis, and Liangshanella; at Walcott Quarry, Liangshanella, Hazelia, and Marrella are the most temporally recurrent taxa. These taxa also have wide geographic ranges, further suggesting that long periods of compositional stasis were maintained by a subset of taxa with long survivorship, likely due to high dispersal and/or colonization ability (Foote 2003; Payne and Finnegan 2007; Hopkins 2011). 


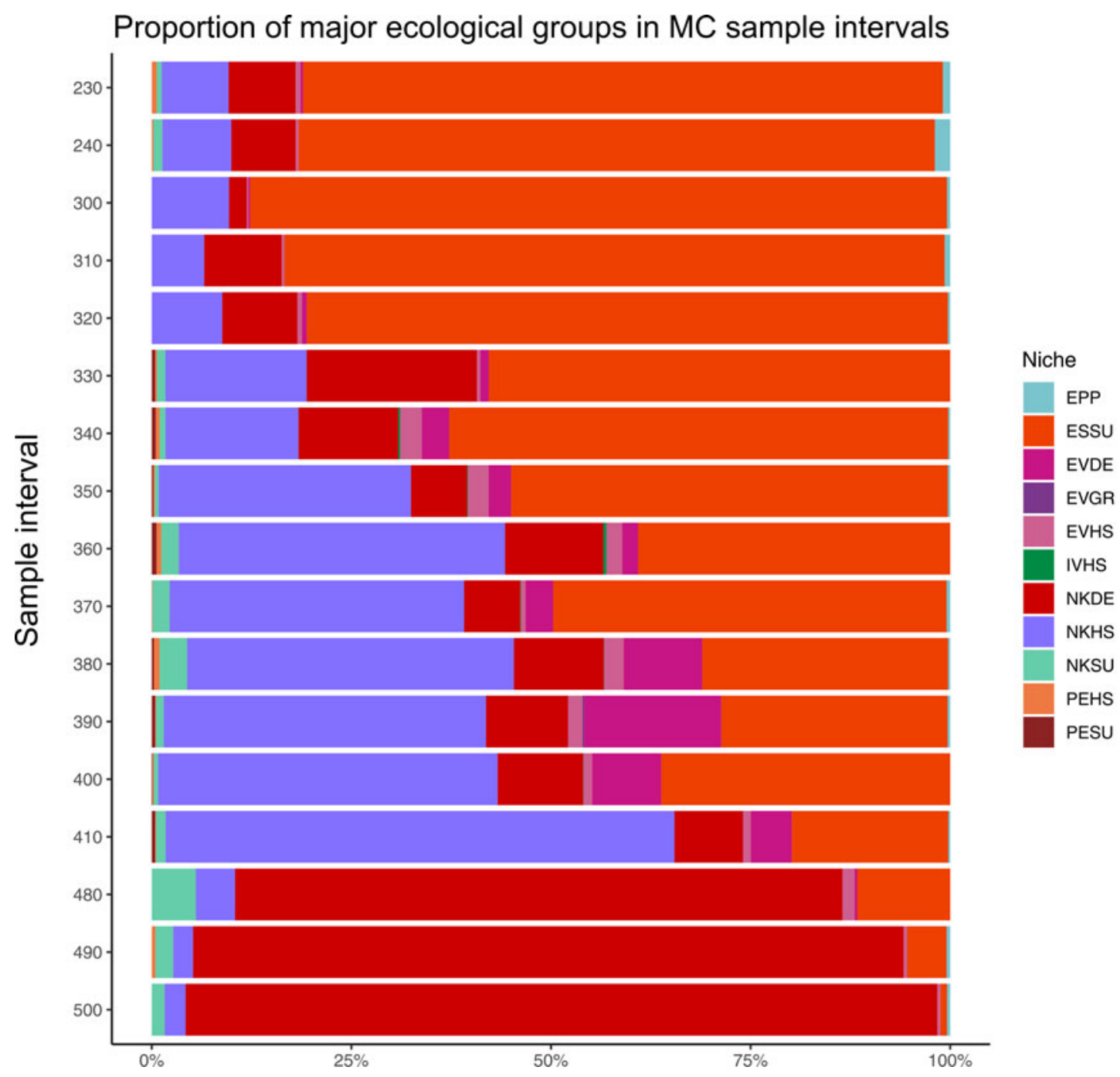

FIGURE 8. Proportions of major ecological groups among the Marble Canyon (MC) sample intervals (see Fig. 1). The upper levels of the quarry are largely composed of epibenthic-sessile-suspension feeders. As arthropods become more abundant, nektonic-vagrant-hunter/scavengers become the dominant ecological group. The lowest three SIs in the quarry are dominated by epibenthic-vagrant-deposit feeders. Acronyms: EPP, epibenthic primary producer; ESSU, epibenthic-sessile-suspension feeder; EVDE, epibenthic-vagrant-deposit feeder; EVGR, epibenthic vagrant grazer; EVHS, epibenthic vagrant hunter/scavenger; IVHS, infaunal vagrant hunter scavenger; NKDE, nektobenthic deposit feeder; NKHS, nektobenthic hunter scavenger; NKSU, nektobenthic suspension feeder; PEHS, pelagic hunter scavenger; PESU, pelagic suspension feeder.

The nature of the perturbations that might have resulted in major compositional changes at Marble Canyon as well as among other Burgess Shale sites (see following section) must remain speculative. A variety of abiotic factors are known to result in major changes in modern marine community diversity and structure (Sousa 1984; Conversi et al. 2015) such as shifting temperatures and perturbations of ocean chemistry at ecologically relevant timescales (Harley et al. 2006; Bornette and Puijalon 2011). The near-total absence of sponges from Marble Canyon could be due to either turbid conditions impairing their ability to feed (Pineda et al. 2017) or to a lack of an appropriate substrate for larval recruitment (Maldonado and Young 1996; Whalan et al. 2015). While we are unable at this time to provide a 


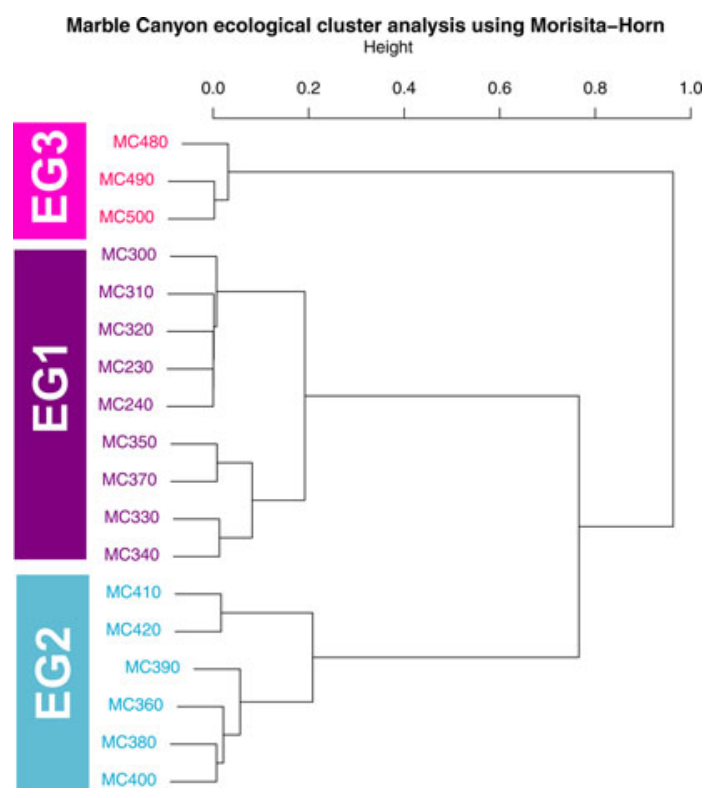

Figure 9. Cluster analysis for the Marble Canyon (MC) ecological abundance matrix using the Morisita-Horn index. Three major clusters are recovered, corresponding to the uppermost levels of the upper quarry (EG1), the lower levels of the upper quarry (EG2), and the lower quarry (EG3).

mechanistic correlate for changes in faunal composition we observed, the most significant of these changes (after which community structure remained relatively stable for thousands of years) may have been caused by similarly broad-scale environmental fluctuations. Testing this hypothesis would require additional explanatory proxies, including the potential availability of geochemical data, in the future.

Macroecological Patterns of Paleocommunity Structure across the Burgess Shale.-Major patterns of taxonomic compositional change observed within and between localities are at odds with a random distribution of taxa from a single species pool. One of the most striking examples of this temporal variation in species composition among localities is the abundance of sponges. They are the second most diverse phylum at the Tulip Beds and Walcott Quarry, and the second most abundant phylum at the Walcott Quarry and Raymond Quarry, but at Marble Canyon, only 5 specimens out of 16,438 are sponges. The priapulids are similarly abundant throughout most well- studied Cambrian localities, particularly at the Raymond Quarry, where Ottoia alone makes up $10.1 \%$ of specimens from our sampled interval. At Marble Canyon, however, only a few specimens of Selkirkia and an as-of-yet indeterminate priapulid represent this phylum. Other taxa show a systematic increase in abundance from older to younger localities. While hemichordates are absent from the Tulip Beds, each of the younger localities has a different hemichordate taxon that is prevalent enough to be an indicator species (Spartobranchus, an undescribed enteropneust, and Oesia for Walcott Quarry, Raymond Quarry, and Marble Canyon, respectively). The only annelid at the Tulip Beds is a single specimen of Burgessochaeta. By contrast, the younger Walcott Quarry and Marble Canyon possess significant numbers of annelids (Burgessochaeta and Kootenayscolex, respectively).

A number of possibilities exist to explain the high degree of taxonomic heterogeneity among our sampled localities. The first are ecological interactions mediating species distributions. Interspecific competition leading to competitive exclusion may have sequentially excluded species from younger localities (Hardin 1960). For example, sponges may have been systematically outcompeted in the epifaunal suspensionfeeding niche by taxa such as Haplophrentis (Moysiuk et al. 2017) and Oesia (Nanglu et al. 2016). The near-complete absence of Burgessochaeta may be due to its niche being filled by Kootenayscolex, which is thought to have shared a similar mode of life (Caron and Jackson 2008; Nanglu and Caron 2018). The same could be argued of other taxa that presumably shared a significant degree of ecological overlap and show a similar pattern of distributional turnover, such as Yawunik (Aria et al. 2015) and Tokummia (Aria and Caron 2017) at Marble Canyon, possibly filling the ecospace of Leanchoilia and Branchiocaris from older localities. However, biotic drivers of community assembly, such as competition (Connell 1961a,b; McCook et al. 2001) or dispersal ability (Rosindell et al. 2011; Klompmaker and Finnegan 2018), are difficult to test in a paleontological setting and thus remain speculative.

Our view of Cambrian trophic ecology is also impacted through our quantitative SI-level 


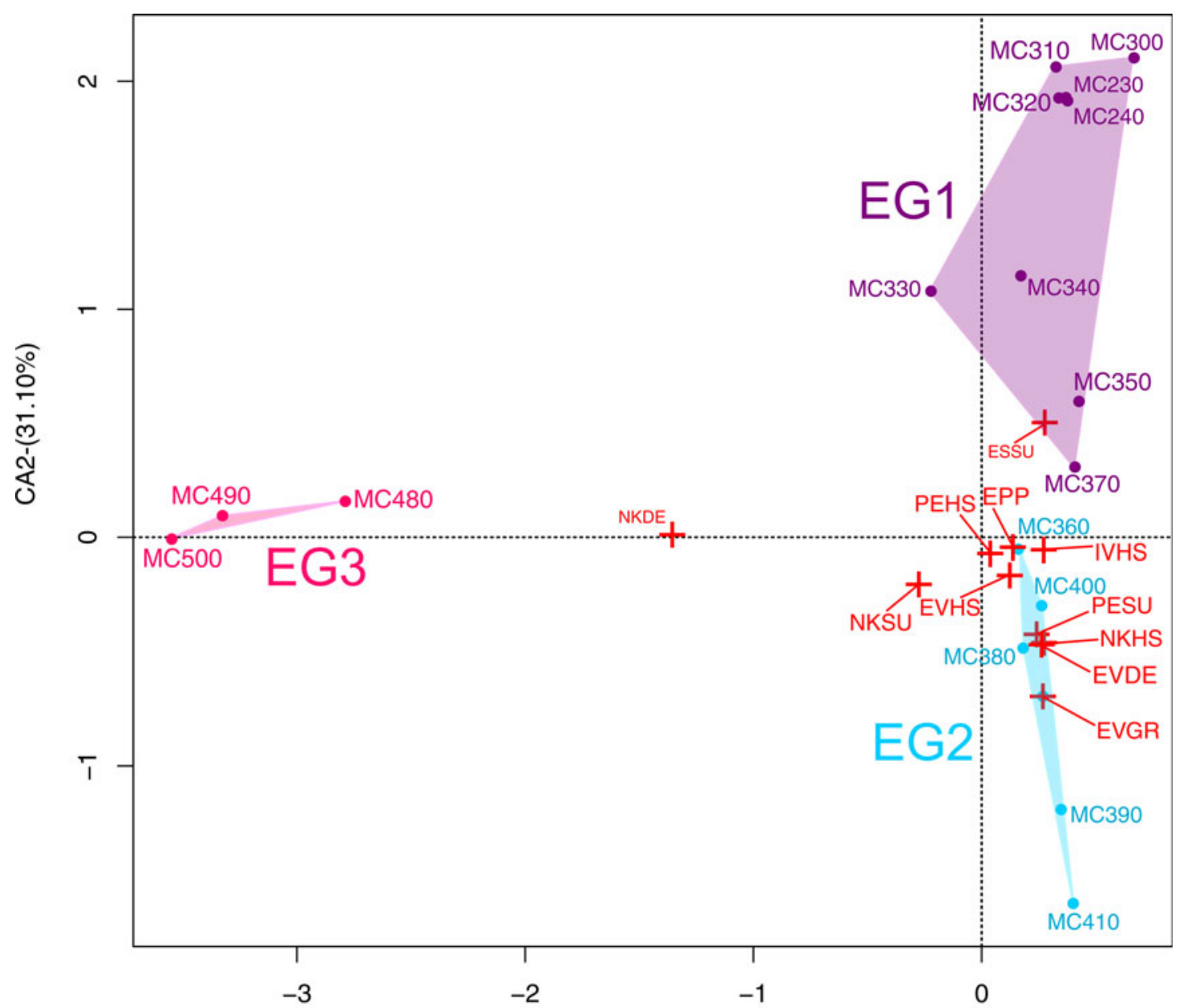

CA1-(59.48\%)

FIGURE 10. Ecological correspondence analysis (CA) for the Marble Canyon (MC) quarry, with convex hulls corresponding to SI clusters recovered by ecological cluster analysis (Figure 9). There are three main types of ecological groups: those dominated by epibenthic-sessile-suspension feeding (ESSU; purple) those dominated by nektobenthic-vagrant-hunter/ scavengers (NKHS; blue), and those dominated nektobenthic-vagrant-deposit feeding (NKDE; pink). Acronyms: EPP, epibenthic primary producer; EVDE, epibenthic-vagrant-deposit feeder; EVGR, epibenthic vagrant grazer; EVHS, epibenthic vagrant hunter/scavenger; IVHS, infaunal vagrant hunter scavenger; NKSU, nektobenthic suspension feeder; PEHS, pelagic hunter scavenger; PESU, pelagic suspension feeder. Please see the online version of this article for full color.

analysis of multiple localities. The view that Cambrian paleocommunities were relatively stable in ecological structure has been largely based on limited comparisons between sites at the level of broadly sampled bulk assemblages without quantitative comparisons of how within-locality ecological fluctuations compared across localities (Zhao et al. 2013; O'Brien and Caron 2015). For example, a bulk assemblage comparison of the Tulip Beds and Walcott Quarry indicated that there was a broadly similar diversity of ecological strategies (and that this pattern was also shared with the Chengjiang localities; O'Brien and Caron 2015). Our data suggest that if we consider fine-scale stratigraphic variation rather than combining the ecologies of each major locality into a single pool, the dominant ecological modes were susceptible to considerable variation. SIs may be more similar in ecological structure to temporally disjunct SIs than to their stratigraphically adjacent neighbors. In this 


\section{Burgess Shale cluster analysis using Morisita-Horn}

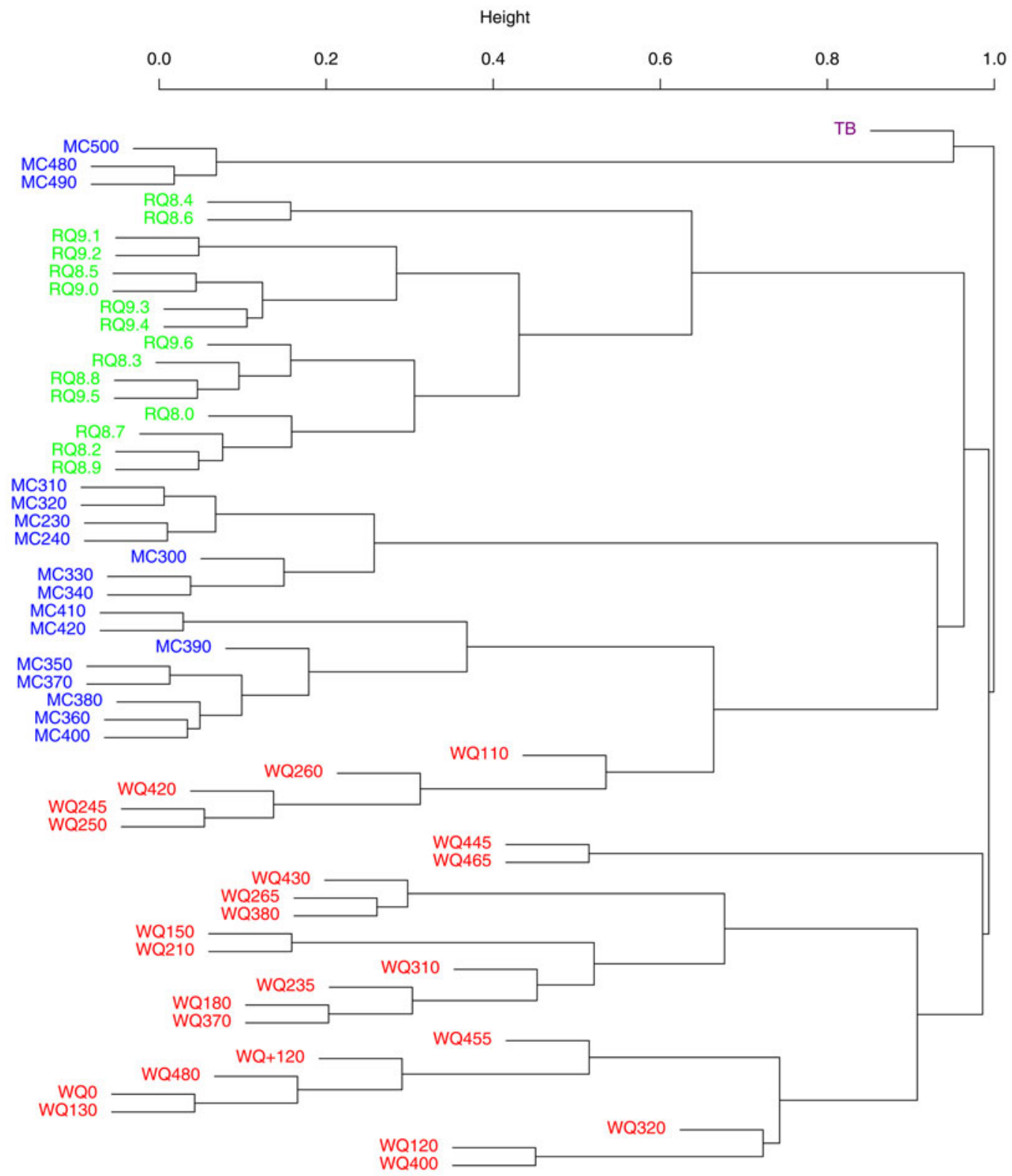

FIGURE 11. Taxonomic cluster analyses for the Walcott Quarry (WQ), Raymond Quarry (RQ), Tulip Beds (TB), and Marble Canyon (MC) using the Morisita-Horn index recovers most sample intervals (SIs) in close association with SIs from the same locality. Notable exceptions are the clustering of Upper Quarry 2 SIs from MC with select WQ SIs, and the Lower Quarry SIs from MC as clustered with the TB locality. Please see the online version of this article for full color. 
TABLE 1. Species indicator analysis for the Burgess Shale. The indicator statistic has two components. The A component describes the likelihood of sampling from the indicated locality (or group of localities) based on the presence of the indicator taxon. The B component describes the likelihood of finding the indicator taxon when sampling from the indicated locality (or group of localities).

\begin{tabular}{|c|c|c|c|c|c|}
\hline Localities & Indicator taxon & A component & B component & Indicator statistic & $p$-value \\
\hline \multirow[t]{8}{*}{ Marble Canyon (MC) } & Oesia disjuncta & 0.9980 & 1.0000 & 0.999 & 0.005 \\
\hline & New arthropod J & 1.0000 & 0.9444 & 0.972 & 0.005 \\
\hline & Indet. worm A & 1.0000 & 0.8333 & 0.913 & 0.015 \\
\hline & Tokummia & 1.0000 & 0.8333 & 0.913 & 0.020 \\
\hline & Metaspriggina & 0.9736 & 0.8333 & 0.901 & 0.020 \\
\hline & Yawunik & 1.0000 & 0.7778 & 0.882 & 0.020 \\
\hline & Cyanobacteria-MC & 1.0000 & 0.6667 & 0.816 & 0.045 \\
\hline & Ptychoparid-MC & 0.9909 & 0.6667 & 0.813 & 0.035 \\
\hline \multirow[t]{7}{*}{ Raymond Quarry (RQ) } & Herpetogaster collinsi & 0.9536 & 1.0000 & 0.977 & 0.005 \\
\hline & Allonia & 1.0000 & 0.9333 & 0.966 & 0.005 \\
\hline & Fuxianospira & 0.9365 & 0.9333 & 0.935 & 0.005 \\
\hline & Medusoid-RQ & 1.0000 & 0.8667 & 0.931 & 0.020 \\
\hline & Helcionellid & 1.0000 & 0.8000 & 0.894 & 0.035 \\
\hline & Enteropneust RQ-A & 1.0000 & 0.8000 & 0.894 & 0.045 \\
\hline & Naraoia magna & 1.0000 & 0.2000 & 0.447 & 0.035 \\
\hline \multirow[t]{4}{*}{ Walcott Quarry (WQ) } & Burgessia bella & 1.0000 & 0.9583 & 0.979 & 0.005 \\
\hline & Ptychagnostus praecurrens & 0.9624 & 0.9583 & 0.960 & 0.005 \\
\hline & Morania sp. & 1.0000 & 0.9167 & 0.957 & 0.005 \\
\hline & Spartobranchus tenuis & 0.9588 & 0.8333 & 0.894 & 0.035 \\
\hline \multirow[t]{3}{*}{ Tulip Beds (TB) } & Ogygopsis klotzi & 1.0000 & 1.0000 & 1.0000 & 0.035 \\
\hline & Glossopleura & 1.0000 & 1.0000 & 1.0000 & 0.035 \\
\hline & Siphusauctum gregarium & 1.0000 & 1.0000 & 1.0000 & 0.035 \\
\hline $\mathrm{MC}+\mathrm{TB}$ & Peronopsis & 0.9992 & 1.0000 & 1.0000 & 0.005 \\
\hline \multirow[t]{9}{*}{$\mathrm{RQ}+\mathrm{TB}$} & Anomalocaris canadensis & 0.9994 & 1.0000 & 1.000 & 0.005 \\
\hline & Vauxia sp. & 0.9925 & 1.0000 & 0.996 & 0.005 \\
\hline & Tubullela sp. & 0.9861 & 1.0000 & 0.993 & 0.005 \\
\hline & Leanchoilia spp. & 0.9783 & 1.0000 & 0.989 & 0.005 \\
\hline & Hurdia sp. & 0.9455 & 1.0000 & 0.972 & 0.005 \\
\hline & Micromitra burgessensis & 0.8999 & 1.0000 & 0.949 & 0.005 \\
\hline & Choia spp. & 0.9798 & 0.8750 & 0.926 & 0.045 \\
\hline & Mackenzia costalis & 0.9664 & 0.8750 & 0.920 & 0.005 \\
\hline & Tuzoia spp. & 0.8156 & 1.0000 & 0.903 & 0.005 \\
\hline \multirow[t]{3}{*}{$\mathrm{RQ}+\mathrm{WQ}$} & Pagetia bootes & 1.0000 & 0.8718 & 0.934 & 0.005 \\
\hline & Pollingeria grandis & 1.0000 & 0.8718 & 0.934 & 0.005 \\
\hline & Olenoides serratus & 1.0000 & 0.8205 & 0.906 & 0.005 \\
\hline \multirow[t]{13}{*}{$\mathrm{WQ}+\mathrm{TB}$} & Wiwaxia corrugata & 1.0000 & 1.0000 & 1.000 & 0.005 \\
\hline & Hazelia spp. & 0.9964 & 1.0000 & 0.998 & 0.005 \\
\hline & Selkirkia spp. & 0.9928 & 1.0000 & 0.996 & 0.005 \\
\hline & Ehmaniella spp. & 0.9889 & 1.0000 & 0.994 & 0.005 \\
\hline & Marrella splendens & 1.0000 & 0.9600 & 0.980 & 0.005 \\
\hline & Scenella amii & 0.9963 & 0.9600 & 0.978 & 0.005 \\
\hline & Yohoia tenuis & 1.0000 & 0.9200 & 0.959 & 0.005 \\
\hline & Canadaspis perfecta & 0.9941 & 0.8800 & 0.935 & 0.010 \\
\hline & Laggania cambria & 1.0000 & 0.8400 & 0.917 & 0.025 \\
\hline & Naraoia spp. & 0.9922 & 0.8400 & 0.913 & 0.030 \\
\hline & Lingulella waptaensis & 0.9762 & 0.8400 & 0.906 & 0.025 \\
\hline & Takakkawia lineata & 0.9535 & 0.7600 & 0.851 & 0.035 \\
\hline & Kootenia burgessensis & 0.9288 & 0.7600 & 0.840 & 0.030 \\
\hline & Liangshanella spp. & 1.0000 & 1.0000 & 1.0000 & 0.035 \\
\hline \multirow{4}{*}{$\mathrm{RQ}+\mathrm{WQ}+\mathrm{TB}$} & Waptia fieldensis & 1.0000 & 0.9500 & 0.975 & 0.005 \\
\hline & Diraphora bellicostata & 1.0000 & 0.9250 & 0.962 & 0.005 \\
\hline & Ottoia prolifica & 1.0000 & 0.9250 & 0.962 & 0.005 \\
\hline & Isoxys spp. & 0.9791 & 0.8750 & 0.926 & 0.005 \\
\hline
\end{tabular}

context, ecological structure throughout the Burgess Shale was highly heterogeneous both at the level of $10 \mathrm{~cm}$ assemblages and localities.
Predation is often suggested as one of the principal forces structuring communities during the Cambrian (Bengtson 2002; $\mathrm{Hu}$ et al. 2007; Vannier et al. 2007; Vannier 2012; 


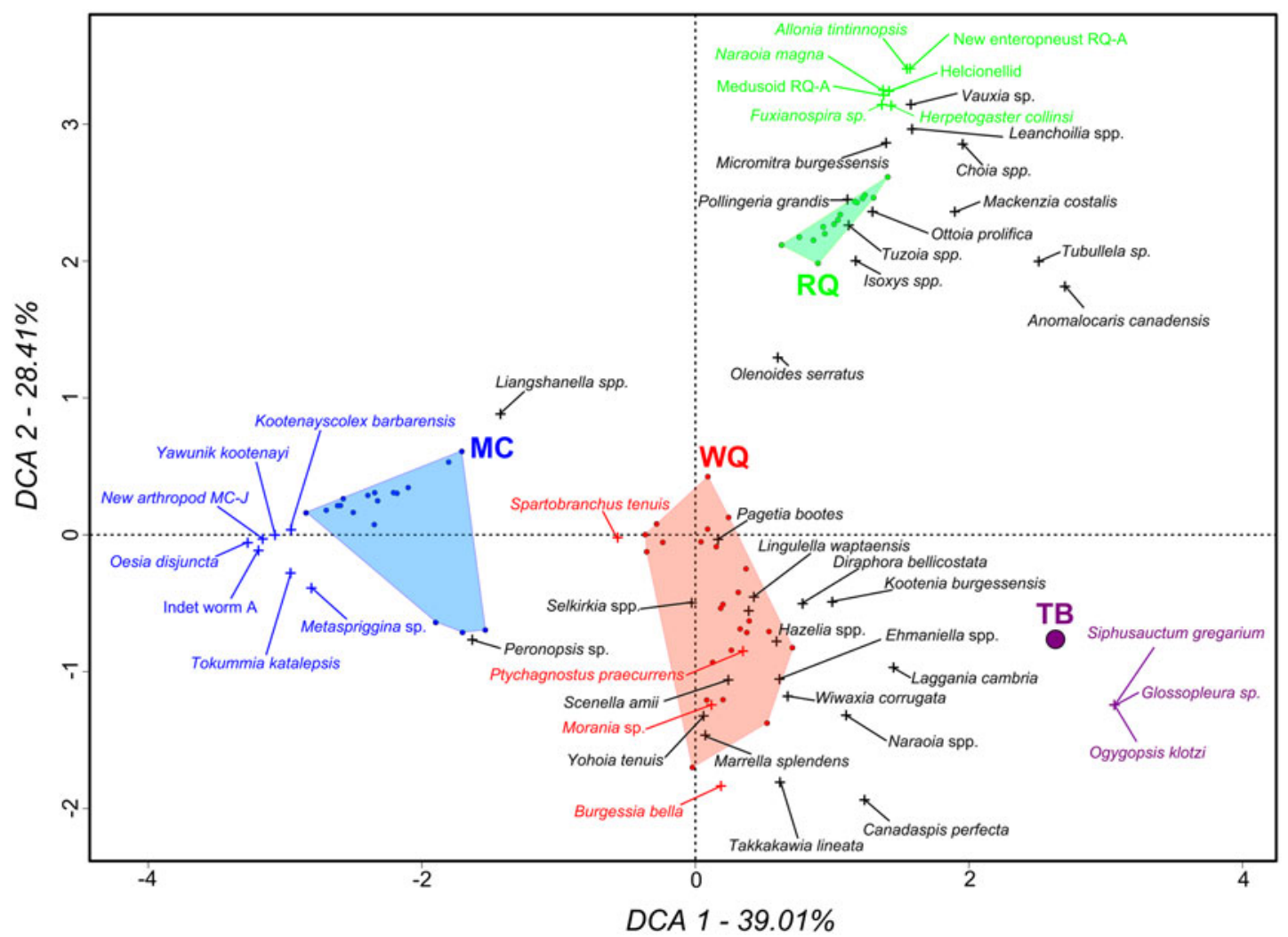

FIGURE 12. Detrended correspondence analysis (DCA) for the Walcott Quarry (WQ; red), Raymond Quarry (RQ, green), Tulip Beds (TB; purple), and Marble Canyon (MC; blue) taxonomic abundance matrix. Indicator species are plotted in the color of their respective localities. Indicator species for groups of more than one locality are plotted in black.

Laflamme et al. 2013), as well as one of the factors most distinguishing Cambrian communities from the preceding Ediacaran fauna (Laflamme and Narbonne 2008; Xiao and Laflamme 2009). In our analyses, the epifaunal suspension feeding-dominated SIs are the largest cluster, suggesting that this mode of life was at least as important as predation for defining paleocommunity ecological structure. One way of interpreting these data would be to suggest periodic alternation between top-down (predator and competition-mediated) versus bottom-up (prey and environment-mediated) control of community ecology (Roff et al. 2016). However, it has been noted that this dichotomy may not be appropriate in marine settings, as these mechanisms are not mutually exclusive (Ruppert et al. 2013; Conversi et al. 2015). For example, many predatory species have larval forms (which we are unlikely to see in the fossil record, except in the most exceptional of circumstances; Maas et al. 2006; Yin et al. 2007) that are highly sensitive to environmental conditions, while sessile organisms are frequently in direct competition for substrate (McCook et al. 2001). It is, therefore, most appropriate to view the structure of Cambrian paleocommunities as we now view modern benthic communities: the result of multiple interspecific drivers such as predation (Connell 1961a), competition (Connell 1961b; Paine 1974; McCook et al. 2001; Hixon and Jones 2005), niche partitioning (MacArthur 1958), and dispersal (Hubbell 2001) acting simultaneously on the backdrop of abiotic factors such as environmental perturbation (Krebs 2009; Conversi et al. 2015; Pershing et al. 2015).

\section{Conclusions}

While our understanding of the Cambrian explosion continues to progress, the discovery 
Burgess Shale ecological cluster analysis using Morisita-Horn Height

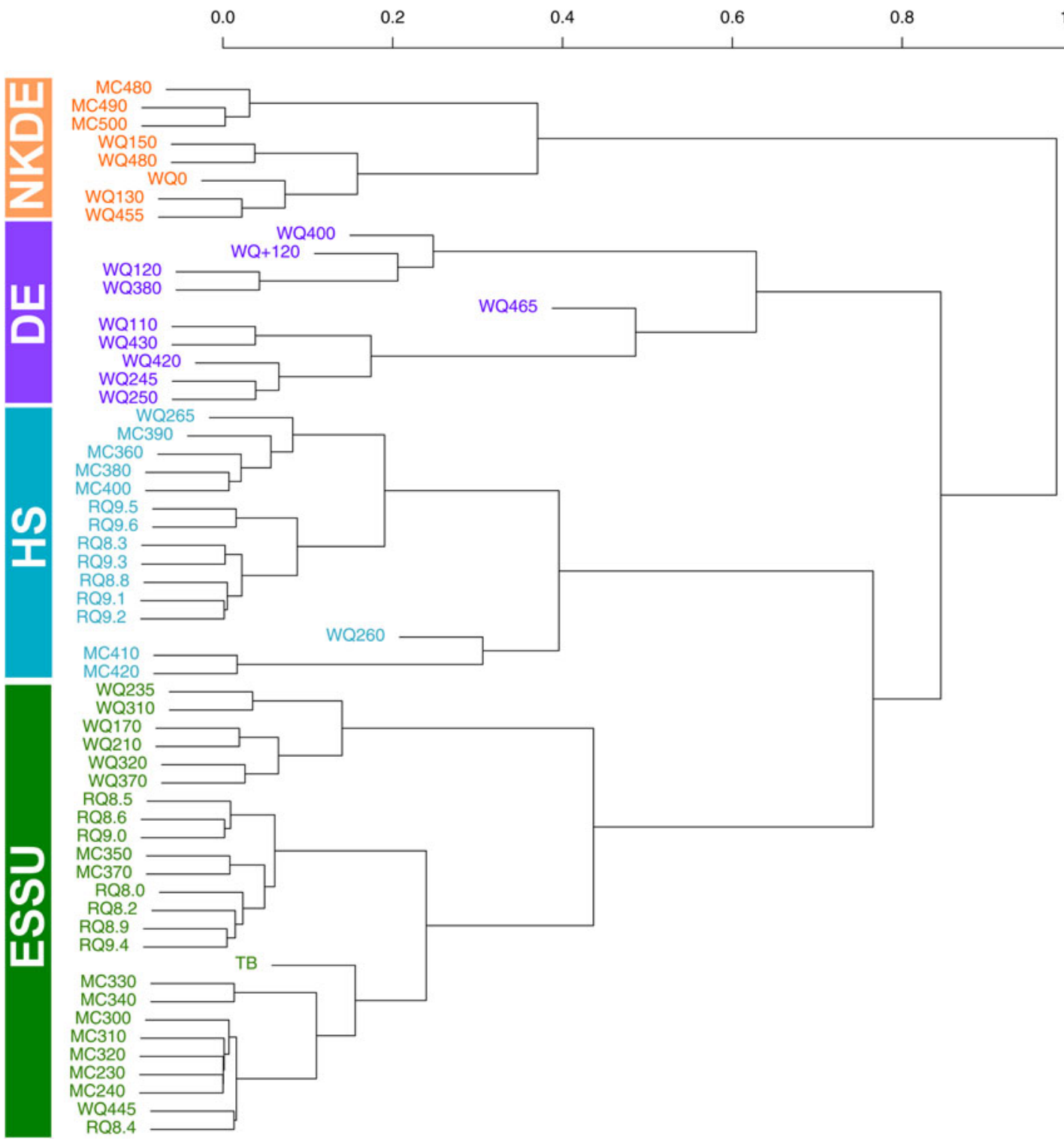

FIGURE 13. Ecological cluster analyses for the Walcott Quarry (WQ), Raymond Quarry (RQ), Tulip Beds (TB), and Marble Canyon (MC) using the Morisita-Horn index. Four main clusters are recovered dominated by three different trophic modes: suspension feeding (ESSU; green); hunting/scavenging (HS; blue); deposit feeding (DE; purple; and NKDE; orange). Please see the online version of this article for full color.

of the Marble Canyon fossil site clearly demonstrates that major discoveries at the level of entire faunas remain to be made. Such discoveries have the potential to shed light not only on the early origins of nearly all major metazoan phyla, but also on the structure and diversity of Cambrian ecosystems. Our study represents the first quantitative analysis of the four best-sampled Burgess Shale localities and the largest analysis of a Cambrian Burgess Shale-type paleocommunity to date. The integration of fine-resolution stratigraphic data 


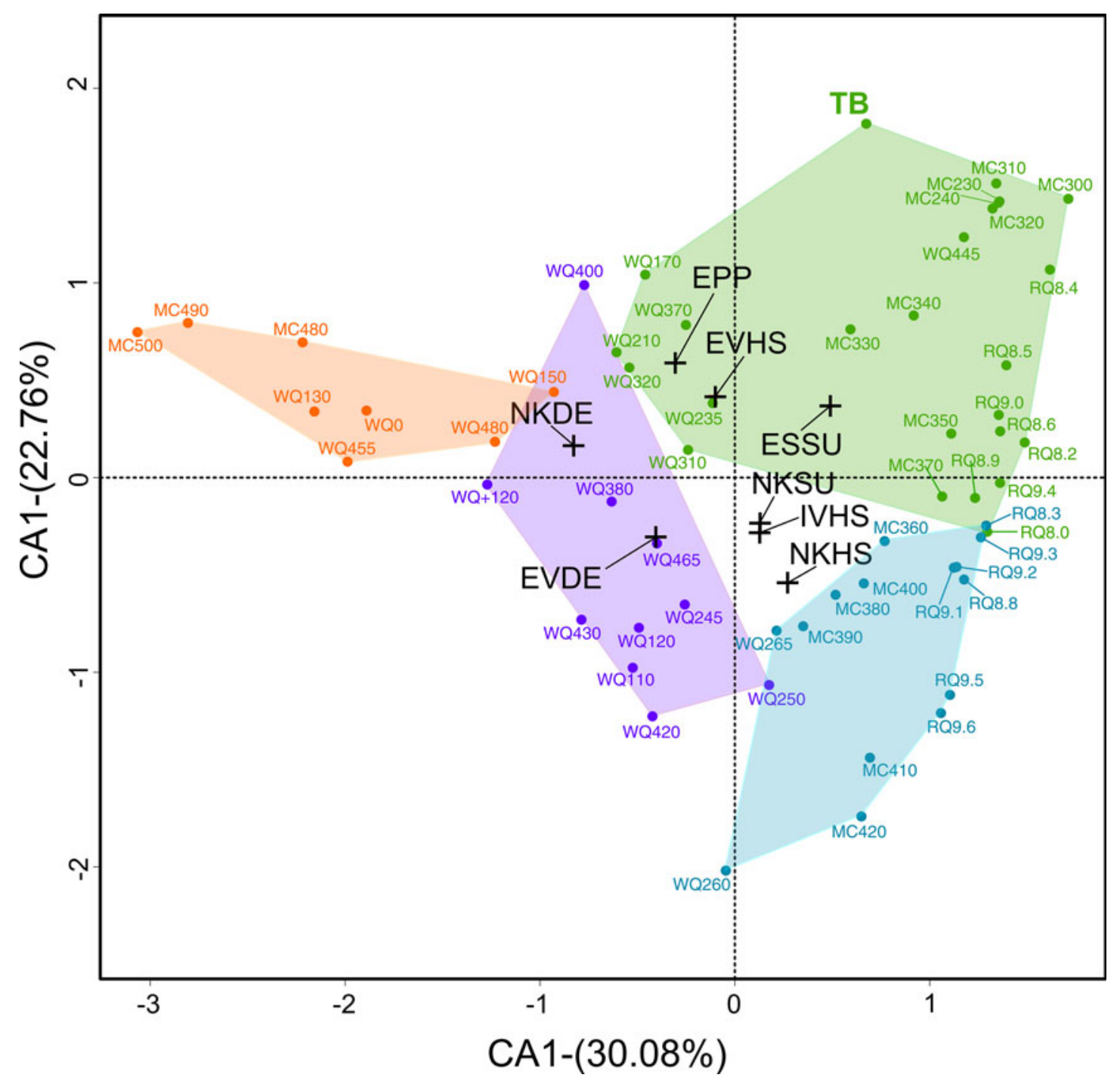

FIGURE 14. Ecological correspondence analysis (CA) for the Walcott Quarry (WQ), Raymond Quarry (RQ), Tulip Beds (TB), and Marble Canyon (MC). Convex hulls are plotted and colored according to the results of the ecological cluster analysis (Fig. 11). For clarity, only highly recurrent ecological modes are plotted. See Fig. 8 for acronyms.

possesses significant promise for disentangling the potential mechanisms behind the assembly of some of the earliest complex animal paleocommunities. SI-level changes in both taxonomic and ecological structure show that fluctuations between periods of relative stasis and rapid compositional change are characteristic among Cambrian localities at short timescales. Widening the scope of our observations to stratigraphically disparate localities reveals that the dominance of different ecological modes was patchy throughout the
Burgess Shale and that major taxonomic changes occurred within and between localities. These data indicate that the Burgess Shale was highly heterogeneous with respect to ecology and species composition at both ecological and geologic timescales.

\section{Acknowledgments}

We thank P. Fenton and M. Akrami for collections assistance at the Royal Ontario Museum, E. Welsh for help with data entry 
(Raymond Quarry), and T. M. Cullen and M. Orobko for discussions and help with $\mathrm{R}$ coding. H. Cyr, D. Currie, M. Aberhan, M. Patzkowsky, and two anonymous reviewers provided helpful comments on an earlier draft of this article. Material for this study was collected under several Parks Canada Research and Collections permits (to J.-B.C.). Major funding support for fieldwork comes from Barbara Polk Milstein and several Royal Ontario Museum grants (to J.-B.C.), the National Geographic Society (2014 research grant to J.-B.C.), the National Science Foundation (2011 EAR-1046233 and 2016 EAR-1556226 awards to R.R.G.-Pomona College). K.N.'s doctoral research was supported by fellowships from the University of Toronto (Department of Ecology and Evolutionary Biology) and J.-B.C.'s NSERC Discovery Grant (number 341944). This is Royal Ontario Museum Burgess Shale project number 81.

\section{Literature Cited}

Aitken, J. D. 1997. Stratigraphy of the Middle Cambrian platformal succession, southern Rocky Mountains. Geological Survey of Canada Bulletin 398:322

Aria, C., and J. B. Caron. 2015. Cephalic and limb anatomy of a new isoxyid from the Burgess Shale and the role of "stem bivalved arthropods" in the disparity of the frontalmost appendage. PLoS ONE 10:1-37.

Aria, C., and J.-B. Caron. 2017. Burgess Shale fossils illustrate the origin of the mandibulate body plan. Nature 545:89-92.

Aria, C., and J.-B. Caron. 2019. A middle Cambrian arthropod with chelicerae and proto-book gills. Nature 573:586-589.

Aria, C., J.-B. Caron, and R. Gaines. 2015. A large new leanchoiliid from the Burgess Shale and the influence of inapplicable states on stem arthropod phylogeny. Palaeontology 58:629-660

Azaele, S., S. Pigolotti, J. R. Banavar, and A. Maritan. 2006. Dynamical evolution of ecosystems. Nature 444:926-928.

Bambach, R. K., A. M. Bush, and D. H. Erwin. 2007. Autecology and the filling of ecospace: key metazoan radiations. Palaeontology 50:1-22.

Barwell, L. J., N. J. B. Isaac, and W. E. Kunin. 2015. Measuring species-diversity with species abundance data. Journal of Animal Ecology 84:1112-1122.

Beli, E., S. Piraino, and C. B. Cameron. 2017. Fossilization processes of graptolites: insights from the experimental decay of Rhabdopleura sp. (Pterobranchia). Palaeontology 60:389-400.

Bengtson, S. 2002. Origins and early evolution of predation. Paleontological Society 8:289-318.

Bornette, G., and S. Puijalon. 2011. Response of aquatic plants to abiotic factors: a review. Aquatic Sciences 73:1-14.

Butterfield, N. J. 1995. Secular distributions of Burgess Shale-type preservation. Lethaia 28:1-13.

Caron, J.-B., and D. A. Jackson. 2006. Taphonomy of the Greater Phyllopod Bed community, Burgess Shale. Palaios 21:451-465.
Caron, J.-B., and D. A. Jackson. 2008. Paleoecology of the Greater Phyllopod Bed community, Burgess Shale. Palaeogeography, Palaeoclimatology, Palaeoecology 258:222-256.

Caron, J. B., R. R. Gaines, M. G. Mángano, M. Streng, and A. C. Daley. 2010. A new Burgess Shale-type assemblage from the "thin" Stephen Formation of the southern Canadian Rockies. Geology 38:811-814.

Caron, J.-B., R. R. Gaines, C. Aria, M. G. Mángano, and M. Streng. 2014. A new phyllopod bed-like assemblage from the Burgess Shale of the Canadian Rockies. Nature Communications 5:3210.

Collins, D. H., D. Briggs, and S. Morris. 1983. New Burgess Shale fossil sites reveal Middle Cambrian faunal complex. Science 222:163-167.

Condit, R., P. S. Ashton, N. Manokaran, J. V LaFrankie, S. P. Hubbell, and R. B. Foster. 1999. Dynamics of the forest communities at Pasoh and Barro Colorado: comparing two 50-ha plots. Philosophical Transactions of the Royal Society of London B 354:1739-1748.

Connell, J. H. 1961a. Effects of competition, predation by Thais lapillus, and other factors on natural populations of the barnacle Balanus balanoides. Ecological Monographs 31:61-104.

Connell, J. H. 1961b. The influence of interspecific competition and other factors on the distribution of the barnacle Chthamalus stellatus. Ecology 42:710-723.

Conversi, A., V. Dakos, A. Gårdmark, S. Ling, C. Folke, P. J. Mumby, C. Greene, M. Edwards, T. Blenckner, M. Casini, A. Pershing, and C. Möllmann. 2015. A holistic view of marine regime shifts. Philosophical Transactions of the Royal Society of London B 370:1-8.

Conway Morris, S. 1986. The community structure of the Middle Cambrian phyllopod bed (Burgess Shale). Palaeontology 29:423-467.

Conway Morris, S., and J.-B. Caron. 2014. A primitive fish from the Cambrian of North America. Nature 512:419-422.

De Cáceres, M., P. Legendre, S. K. Wiser, and L. Brotons. 2012. Using species combinations in indicator value analyses. Methods in Ecology and Evolution 3:973-982.

Devereux, M. G. 2001. Palaeoecology of the Middle Cambrian Raymond Quarry fauna, Burgess Shale, British Columbia. Master's thesis. University of Western Ontario, London, ON, Canada.

Erwin, D. H., M. Laflamme, S. M. Tweedt, E. A. Sperling, D. Pisani, and K. J. Peterson. 2011. The Cambrian conundrum: early divergence and later ecological success in the early history of animals. Science 334:1091-1097.

Findlay, D. L., and S. E. M. Kasian. 1986. Phytoplankton community responses to acidification of lake 223, experimental lakes area, northwestern Ontario. Water, Air, and Soil Pollution 30:719-726.

Fletcher, T., and D. Collins. 1998. The Middle Cambrian Burgess Shale and its relationship to the Stephen Formation in the southern Canadian Rocky Mountains. Canadian Journal of Earth Sciences 35:413-436.

Fletcher, T. P., and D. H. Collins. 2003. The Burgess Shale and associated Cambrian formations west of the Fossil Gully Fault Zone on Mount Stephen, British Columbia. Canadian Journal of Earth Sciences 40:1823-1838.

Foote, M. 2003. Origination and Extinction through the Phanerozoic: a new approach. Journal of Geology 111:125-148.

Gauch, H. G. 1982. Multivariate analysis in community ecology. Cambridge University Press, Cambridge.

Gaines, R. R. 2014. Burgess Shale-type preservation and its distribution in space and time. Paleontological Society Papers 20:123-146.

Gaines, R. R., Hammarlund, E. U., Hou, X., Qi, C., Gabbott, S. E., Zhao, Y., Peng, J., and D. Canfield. 2012. Mechanism for Burgess Shale-type preservation. Proceedings of the National Academy of Sciences USA 109:5180-5184 
Grant, P. R., and B. R. Grant. 2002. Unpredictable evolution in a 30-year study of Darwin's finches. Science 296:707-711.

Hammer, O., and D. Harper. 2006. Paleontological data analysis. Blackwell Publishing, Oxford

Hardin, G. 1960. The competitive exclusion principle. Science 131:1292-1297.

Harley, C. D. G., A. R. Hughes, K. M. Hultgren, B. G. Miner, C. J. B. Sorte, C. S. Thornber, L. F. Rodriguez, L. Tomanek, and S. L. Williams. 2006. The impacts of climate change in coastal marine systems. Ecology Letters 9:228-241.

Hixon, M. A., and G. P. Jones. 2005. Competition, predation, and density-dependent mortality in demersal marine fishes. Ecology 86:2847-2859.

Hopkins, M. J. 2011. How species longevity, intraspecific morphological variation, and geographic range size are related: a comparison using Late Cambrian trilobites. Evolution 65:3253-3273.

Hu, S., M. Steiner, M. Zhu, B. D. Erdtmann, H. Luo, L. Chen, and B. Weber. 2007. Diverse pelagic predators from the Chengjiang Lagerstätte and the establishment of modern-style pelagic ecosystems in the early Cambrian. Palaeogeography, Palaeoclimatology, Palaeoecology 254:307-316.

Hubbell, S. P. 2001. The unified neutral theory of biodiversity and biogeography. Princeton University Press, Princeton, N.J.

Hubbell, S. P. 2005. The neutral theory of biodiversity and biogeography and Stephen Jay Gould. Paleobiology 31:122-132.

Johnston, K. J., P. A. Johnston, and W. G. Powell. 2009. A new, Middle Cambrian, Burgess Shale-type biota, Bolaspidella Zone, Chancellor Basin, southeastern British Columbia. Palaeogeography, Palaeoclimatology, Palaeoecology 277:106-126.

Klompmaker, A. A., and S. Finnegan. 2018. Extreme rarity of competitive exclusion in modern and fossil marine benthic ecosystems. Geology 46:723-726.

Krebs, C. J. 2009. Ecology. Pearson Education, San Francisco, Calif.

Laflamme, M., and G. M. Narbonne. 2008. Competition in a Precambrian world: palaeoecology of Ediacaran fronds. Geology 24:182-187.

Laflamme, M., S. A. F. Darroch, S. M. Tweedt, K. J. Peterson, and D. H. Erwin. 2013. The end of the Ediacara biota: extinction, biotic replacement, or Cheshire Cat? Gondwana Research 23:558-573.

Legendre, P., and L. Legendre. 2012. Numerical ecology. Elsevier, London, 425-520.

Maas, A., A. Braun, X. P. Dong, P. C. J. Donoghue, K. J. Müller, E. Olempska, J. E. Repetski, D. J. Siveter, M. Stein, and D. Waloszek. 2006. The "Orsten": more than a Cambrian Konservat-Lagerstätte yielding exceptional preservation. Palaeoworld 15:266-282.

MacArthur, R. H. 1958. Population ecology of some warblers of northeastern coniferous forests. Ecology 39:599-619.

Magurran, A. E. 2004. Measuring biological diversity. Blackwell Science, Oxford.

Maldonado, M., and C. M. Young. 1996. Effects of physical factors on larval behavior, settlement and recruitment of four tropical demosponges. Marine Ecology Progress Series 138:169-180.

McCook, L. J., J. Jompa, and G. Diaz-Pulido. 2001. Competition between corals and algae on coral reefs: a review of evidence and mechanisms. Coral Reefs 19:400-417.

Moysiuk, J., and J.-B. Caron. 2019. Burgess Shale fossils shed light on the agnostid problem. Proceedings of the Royal Society of London B 286:20182314.

Moysiuk, J., M. Smith, and J.-B. Caron. 2017. Hyoliths are Palaeozoic lophophorates. Nature 541:394-397.

Nanglu, K., and J.-B. Caron. 2018. A New Burgess Shale polychaete and the origin of the annelid head revisited. Current Biology 28:319-326.
Nanglu, K., J.-B. Caron, and C. B. Cameron. 2015. Using experimental decay of modern forms to reconstruct the early evolution and morphology of fossil enteropneusts. Paleobiology 41:460478.

Nanglu, K., J.-B. Caron, S. Conway Morris, and C. B. Cameron. 2016. Cambrian suspension-feeding tubicolous hemichordates. BMC Biology 14:9.

O'Brien, L. J., and J.-B. Caron. 2012. A new stalked filter-feeder from the Middle Cambrian Burgess Shale, British Columbia, Canada. PLoS ONE 7:e29233.

O'Brien, L. J., and J.-B. Caron. 2015. Paleocommunity analysis of the Burgess Shale Tulip Beds, Mount Stephen, British Columbia: comparison with the Walcott Quarry and implications for community variation in the Burgess Shale. Paleobiology 42:27-53.

O'Brien, L. J., Caron, J.-B., and R. R. Gaines. 2014. Taphonomy and depositional setting of the Burgess Shale Tulip Beds, Mount Stephen, British Columbia. Palaios 29:309-324.

Oksanen, J., F. G. Blanchet, M. Friendly, R. Kindt, P. Legendre, D. Mcglinn, P. R. Minchin, R. B. O. Hara, G. L. Simpson, P. Solymos, M. H. H. Stevens, E. Szoecs, and H. Wagner. 2019. vegan:1-296. https://cran.r-project.org/web/packages/vegan/ vegan.pdf. Accessed October 2019.

Paine, R. T. 1974. Intertidal community structure: experimental studies on the relationship between an dominant competitor and its principal predator. Oecologia 15:93-120.

Payne, J. L., and S. Finnegan. 2007. The effect of geographic range on extinction risk during background and mass extinction. Proceedings of the National Academy of Sciences USA 104:10506-10511.

Peng, S., L. E. Babcock, and R. A. Cooper. 2012. The Cambrian period. The Geologic Time Scale 2:437-488.

Pershing, A. J., K. E. Mills, N. R. Record, K. Stamieszkin, K. V. Wurtzell, C. J. Byron, D. Fitzpatrick, W. J. Golet, and E. Koob. 2015. Evaluating trophic cascades as drivers of regime shifts in different ocean ecosystems. Philosophical Transactions of the Royal Society of London B 370:1-9.

Pineda, M. C., B. Strehlow, M. Sternel, A. Duckworth, J. Den Haan, R. Jones, and N. S. Webster. 2017. Effects of sediment smothering on the sponge holobiont with implications for dredging management. Scientific Reports 7:1-15.

Roff, G., C. Doropoulos, A. Rogers, Y. M. Bozec, N. C. Krueck, E. Aurellado, M. Priest, C. Birrell, and P. J. Mumby. 2016. The ecological role of sharks on coral reefs. Trends in Ecology and Evolution 31:395-407.

Rosindell, J., S. P. Hubbell, and R. S. Etienne. 2011. The unified neutral theory of biodiversity and biogeography at age ten. Trends in Ecology and Evolution 26:340-348.

Ruppert, J. L. W., M. J. Travers, L. L. Smith, M. J. Fortin, and M. G. Meekan. 2013. Caught in the middle: combined impacts of shark removal and coral loss on the fish communities of coral reefs. PLoS ONE 8:1-9.

Simberloff, D. S., and E. O. Wilson. 1969. Experimental zoogeography of islands: the colonization of empty islands. Ecology 50:278-296.

Sousa, W. W. 1984. The role of disturbance in natural communities. Annual Review of Ecology and Systematics 15:353-391.

Sundberg, F. A. 1994. Corynexochida and Ptychopariida (Trilobita, Arthropoda) of the Ehmaniella Biozone (Middle Cambrian), Utah and Nevada. Los Angeles County Natural History Museum Contributions in Science 446:137.

Vannier, J. 2012. Gut contents as direct indicators for trophic relationships in the Cambrian marine ecosystem. PLoS ONE 7:e52200. Vannier, J., M. Steiner, E. Renvoisé, S.-X. Hu, and J.-P. Casanova. 2007. Early Cambrian origin of modern food webs: evidence from predator arrow worms. Proceedings of the Royal Society of London B 274:627-633. 
Whalan, S., M. A. Abdul Wahab, S. Sprungala, A. J. Poole, and R. De Nys. 2015. Larval settlement: the role of surface topography for sessile coral reef invertebrates. PLoS ONE 10:1-17.

Xiao, S., and M. Laflamme. 2009. On the eve of animal radiation: phylogeny, ecology and evolution of the Ediacara biota. Trends in Ecology and Evolution 24:31-40.

Yin, L., M. Zhu, A. H. Knoll, X. Yuan, J. Zhang, and J. Hu. 2007. Doushantuo embryos preserved inside diapause egg cysts. Nature 446:661-663.
Zhao, F., S. Hu, J. B. Caron, M. Zhu, Z. Yin, and M. Lu. 2012. Spatial variation in the diversity and composition of the Lower Cambrian (Series 2, Stage 3) Chengjiang Biota, Southwest China. Palaeogeography, Palaeoclimatology, Palaeoecology 346-347:54-65.

Zhao, F., J.-B. Caron, D. J. Bottjer, S. Hu, Z. Yin, and M. Zhu. 2013. Diversity and species abundance patterns of the early Cambrian (Series 2, Stage 3) Chengjiang Biota from China. Paleobiology 40:50-69. 